\title{
Polypeptide functionalized gold nanoparticles for bioanalytical applications
}

\author{
Robert Selegård
}

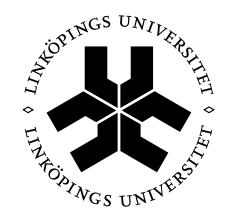

Linköping University INSTITUTE OF TECHNOLOGY

Division of Molecular Physics

Department of Physics, Chemistry and Biology

Linköping University, Sweden

Linköping 2014 
During the course of research underlying this thesis, Robert Selegård was enrolled in Forum Scientium, a multidisciplinary doctoral programme at Linköping University, Sweden.

(C) Copyright 2014 Robert Selegård, unless otherwise noted.

\section{Selegård, Robert}

Polypeptide functionalized gold nanoparticles for bioanalytical applications ISBN: 978-91-7519-321-2

ISSN: 0345-7524

Linköping Studies in Science and Technology. Dissertation No. 1598

Electronic publication: http://www.ep.liu.se

Printed in Sweden by LiU-Tryck, Linköping 2014. 
To Linnéa, Wilhelm and Alfred 

Detection strategies that allow for simple, rapid, cost efficient and sensitive monitoring of proteins and their interactions with biomolecules are of great importance in drug development and diagnostics. This thesis describes the development of bioanalytical applications based on the tunable self-assembly of gold nanoparticles functionalized with a de novo designed polypeptide. Strategies for protein affinity sensing and for detection of several fundamentally important biological processes have been investigated, including $\mathrm{Zn}^{2+}$-mediated coordination between polypeptides and low molecular weight chelants and protease and phosphatase activity.

A $\mathrm{Zn}^{2+}$ responsive synthetic polypeptide designed to fold into a helix-loop-helix motif and dimerize into a four-helix bundle has been used to control the stability and self-assembly of gold nanoparticles. This polypeptide has a high negative net charge at neutral $\mathrm{pH}$ as a consequence of its many glutamic acid residues, efficiently preventing folding and dimerization due to charge repulsion. $\mathrm{Zn}^{2+}$ coordination provides a means to trigger folding and dimerization at neutral $\mathrm{pH}$. The polypeptide can be readily attached to gold nanoparticles via a cysteine residue in the loop region, retaining its folding properties and responsiveness to $\mathrm{Zn}^{2+}$. The polypeptide functionalized gold nanoparticles display excellent colloidal stability but aggregate reversibly after addition of millimolar concentrations of $\mathrm{Zn}^{2+}$. Aggregates are dense with a defined interparticle distance corresponding to the size of the four-helix bundle, resulting in a distinct red shift of the localized surface plasmon resonance band.

Three completely different strategies for colorimetric biosensing have been developed, all being based on the same responsive hybrid nanomaterial. In the first strategy a synthetic receptor was co-immobilized on the gold nanoparticles together with the $\mathrm{Zn}^{2+}$ responsive polypeptide. Protein analyte binding to the receptor could be detected as this interaction sterically prevented aggregation induced by $\mathrm{Zn}^{2+}$. In the second strategy the reduction in colloidal stability caused by specific proteolytic cleavage of the immobilized polypeptide was exploited to monitor the enzymatic activity. The third strategy utilized the sensitivity of the system to small variations in $\mathrm{Zn}^{2+}$ concentration. The presence of low molecular weight chelants was found to influence the mode of aggregation, both by sequestering $\mathrm{Zn}^{2+}$ and through the formation of ternary complexes involving the polypeptides, which prevented dimerization and thus aggregation. This approach was further developed into a generic concept for phosphatase detection exploiting the different affinity of enzyme substrates and reaction products for $\mathrm{Zn}^{2+}$. 
The flexibility of the different detection schemes enables detection of a large number of analytes by exploiting the tunable stability of the nanoparticles and the possibilities to effectively decouple the recognition event and the nanoparticle stability modulation. 


\section{POPULÄRVETENSKAPLIG SAMMANFATTNING}

Proteiner är ytterst viktiga komponenter i våra kroppar där de utför många olika funktioner, såsom katalys av kemiska reaktioner, molekylära transporter, signalering eller uppbyggnad av cellulära strukturer. Dessutom kan ett sjukdomstillstånd vara kopplat till koncentrationsförändringar hos vissa proteiner, så kallade sjukdomsmarkörer. Proteiner interagerar med varandra och med andra biomolekyler. För att studera dessa interaktioner används ett stort antal bioantalytiska metoder som kräver omfattande laborativt arbete eller dyra instrumentella verktyg. Baserat på framsteg som gjorts inom nanomaterialområdet har på senare tid nya analysmetoder utvecklats som är snabba, känsliga och billiga. Speciellt intressant är utvecklingen av nanomaterial som kan ge en gradvis färgförändring på grund av en proteininteraktion, vilket i princip gör det möjligt att se proteinernas interaktioner med blotta ögat. Dessa kolorimetriska detektionssystem är dessvärre ofta skräddarsydda för en specifik interaktion eller det protein man avser att studera.

Denna avhandling visar hur man på ett innovativt sätt kan använda ett och samma nanomaterial för att detektera och analysera flera olika typer av proteiner och för att studera deras funktion. Detta är speciellt intressant eftersom dessa strategier kan användas dels för att undersöka hur potentiella läkemedel påverkar ett proteins funktion, dels för att upptäcka sjukdomsmarkörer i ett tidigt skede och på så vis underlätta behandlingen.

Nanomaterialet som behandlas i avhandlingen består av små syntetiska proteiner, så kallade peptider, som kemiskt bundits till en nanopartikel av guld. Peptiderna har utformats för att parvis interagera med varandra så att de bildar en specifik tredimensionell struktur. Interaktionen sker inte spontant utan initieras i närvaro av zinkjoner. Guldnanopartiklarna är i storleksordningen 20 nanometer (20 miljarddels meter). Material som reducerats till nanometerstorlek kan uppvisa förändrade eller helt nya egenskaper. Guld är till exempel inte längre metalliskt gult utan vinrött men kan också anta en blå-grå nyans om partiklarna klumpar ihop sig och bildar aggregat.

Genom att fästa peptiderna på guldpartiklarnas yta kan närvaro av zinkjoner få peptiderna att interagera med varandra, vilket leder till att partiklarna aggregerar och ger upphov till en färgförändring. Flera variationer av detta fenomen har använts för att skapa olika typer av nya bioanalytiska verktyg. Genom att fästa ytterligare peptider på partikelns yta som har till uppgift att känna igen ett specifikt målprotein och binda det till ytan av partikeln försvåras den zinkberoende aggregeringen eftersom det skrymmande proteinet är i vägen. Den uteblivna färgförändringen gör att närvaro av målproteinet i en lösning kan upptäckas. En annan egenskap hos vissa proteiner som utnyttjats i avhandlingen är deras förmåga att fungera 
som katalysatorer i kemiska reaktioner. Detta är möjligt i de fall där start- och slutmaterialet i reaktionen binder zinkjoner olika starkt och därmed påverkar den fria zinkkoncentrationen i lösningen i olika grad. Partiklarna reagerar och ger en färgförändring som beror på denna koncentration vilket kan användas för att detektera proteinet men också för att studera hur det påverkas av olika läkemedel. Ett flertal ytterst viktiga reaktioner i kroppen har denna påverkan på en zinklösning, bland annat reaktioner som berör den biologiska energibalansen och är fundamentala för allt liv. Nanomaterialet har även använts för att detektera en sjukdomsmarkör för salivkörtelcancer och för att studera hur biomolekyler interagerar med syntetiska proteiner med hjälp av zinkjoner. 
Mina år som doktorand börjar närma sig sitt slut. Tiden som gått har stundtals varit produktiv, mesta dels improduktiv, väldigt rolig, förbaskat kämpig, rent av deprimerande och sammanfattningsvis helt fantastisk. Under den tid som gått har jag lärt mig massor men framför allt vuxit som person både psykiskt och fysiskt. Genom den här resan har jag stött på massor av trevliga, hjälpsamma och kunniga människor som jag således vill tacka.

Jag vill tacka min huvudhandledare Bo Liedberg för att ha gett mig den här chansen, utan dig hade inget av det här varit möjligt, tack. Karin Enander, min biträdande handledare, tack för allt ditt osvikliga stöd, för att du alltid haft din dörr öppen för mig och för att du delat med dig av din kunskap, tack. Daniel Aili, min andra biträdande handledare, tack för ditt osvikliga engagemang, för att du alltid tar dig tid och för att du gjort den här avhandlingen möjlig, tack. I would also like to thank and acknowledge, Peng Chen and Martin Mak for fruitful collaborations. Tack också till Stefan Klintström och Charlotte Immerstrand för ert engagemang i forskar skolan Forum Scientium som gett mig möjlighet att vidga mina vyer.

Jag skulle också vilja tack alla nuvarande och tidigare medlemmar i grupperna molekylär fysik och molekylär ytfysik och nanovetenskap för lärorika möten, sammarbeten och samtal men också för vunna vänskaper, trevliga luncher och välbehövliga fikapauser, tack. Tack till alla er som jag inte nämnt men som jag lunchat och fikat med och som gjort IFM till en fantastisk arbetsplats. Tack till FÖK (Fredags Öl Klubben) för att ni förgyllt mina fredagar.

Jag skulle också vilja tacka min familj, trots att ni kanske inte riktigt förstått vad jag pysslat med under alla dessa år har ni ändå lyssnat intresserat, tack för att ni alltid finns där.

Mina svärföräldrar för att ni alltid ställer upp i vått och torrt, tack.

Slutligen, Linnéa, Wilhelm och Alfred, för att det är ni som är det viktiga här i livet, med kärlek, tack. 


\section{LIST OF PUBLICATIONS}

This thesis is based on the following papers;

I. D. Aili, R. Selegård, L. Baltzer, K. Enander, B. Liedberg

Colorimetric Protein Sensing by Controlled Assembly of Gold Nanoparticles Functionalized with Synthetic Receptors

Small 2009; 5, 2445-2452.

II. P. Chen, R. Selegård, D. Aili, B. Liedberg

Peptide Functionalized Gold Nanoparticles for Colorimetric Detection of Matrilysin (MMP-7) Activity

Nanoscale 2013; 5, 8973-8976.

III. W. C. Mak, ${ }^{\dagger}$ R. Selegård, ${ }^{\dagger}$ M. Garbrecht, D. Aili

Probing Zinc-Protein-Chelant Interactions using Gold Nanoparticles

Functionalized with Zinc-Responsive Polypeptides

${ }^{\dagger}$ Equal contributions

2014, Submitted

IV. R. Selegård, K. Enander, D. Aili

Generic Phosphatase Activity Detection using Zinc Mediated Aggregation Modulation of Polypeptide-Modified Gold Nanoparticles

2014, Submitted 
I. Contribution: R.S did the measurements and compiled the data on C-pTMVP.

II. Contribution: R.S synthesized the polypeptides, designed and carried out control measurements and participated in the writing.

III. Contribution: R.S was involved in experimental design, and responsible for planning, performing and evaluation of experiments. R.S did most of the writing.

IV. Contribution: R.S was involved in experimental design, and responsible for planning, performing and evaluation of experiments. R.S did most of the writing.

The peptides used in this thesis were originally design by Johan Rydberg, Sarojini Vijayalekshmi and Karin Enander in the group of Professor Lars Baltzer, and later refined by Daniel Aili and Karin Enander.

The nanoparticle system used was conceived and developed by Daniel Aili.

Thank you all for your hard work and allowing me to utilize these amazing materials. 


\section{PUBLICATION NOT INCLUDED IN THIS THESIS}

Y. Wang, D. Aili, R. Selegård, Y. Tay, L. Baltzer, H. Zhang, B. Liedberg

Specific functionalization of CTAB stabilized anisotropic gold nanoparticles with polypeptides for folding-mediated self-assembly

Journal of Materials Chemistry 2012; 22, 20368-20373. 
ALP

ATP

Boc

CD

Fmoc

GTP

HCA

RP-HPLC

HSA

LSPR

MALDI-TOF

MMP-7

MS

NMR

NTP

$P_{i}$

$\mathrm{PP}_{\mathrm{i}}$

SAM

SNA

SPPS

TFA

TMVP

UV
ALkaline Phosphatase

Adenosine 5'-TriPhosphatse

tert-Butyloxycarbonyl

Circular Dichroism

Fluorenylmethyloxycarbonyl

Guanosine 5'-triphosphatse

Human Carbonic Anhydrase

Reversed Phase High-performance Liquid Chromatography

Human Serum Albumin

Local Surface Plasmon Resonance

Matrix-Assisted Laser Desorption Ionization Time Of Flight

Matrix MetalloProteinase 7

Mass Spectrometry

Nuclear Magnetic Resonance

Nucleoside 5'-TriPhosphatse

Inorganic Phosphate

PyroPhosphate

Self-Assembled Monolayer

Spherical Nucleic Acid

Solid Phase Peptide Synthesis

TriFluoroacetic Acid

Tobacco Mosaic Virus coat Protein

Ultra Violet 
The one- and three-letter abbreviation of the twenty common amino acids.

\section{Amino Acid}

Alanine

Arginine

Asparagine

Aspartic acid

Cysteine

Glutamine

Glutamic acid

Glycine

Histidine

Isoleucine

Leucine

Lysine

Methionine

Phenylalanine

Proline

Serine

Threonine

Tryptophan

Tyrosine

Valine
Three-letter

abbreviation

Ala

Arg

Asn

Asp

Cys

Gln

Glu

Gly

His

Ile

Leu

Lys

Met

Phe

Pro

Ser

Thr

Trp

Tyr

Val
One-letter

abbreviation

A

R

$\mathrm{N}$

D

C

Q

E

G

H

I

L

K

M

F

P

S

$\mathrm{T}$

W

Y

V 
Introduction ............................................................................................................................... 1

Bionanotechnology and Self-Assembly............................................................................... 5

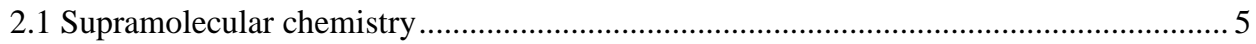

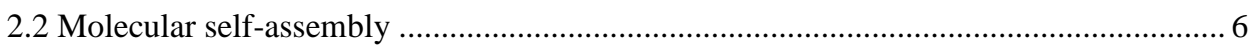

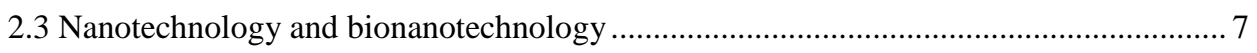

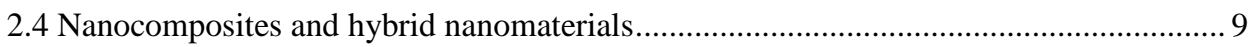

Structure of Proteins and Protein Folding.......................................................................... 11

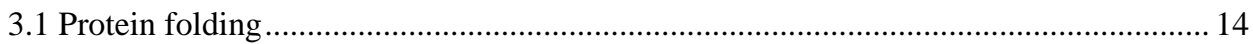

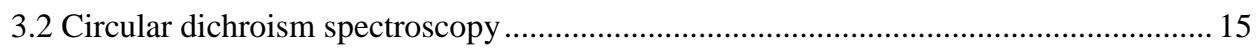

Synthetic Peptides .................................................................................................................. 17

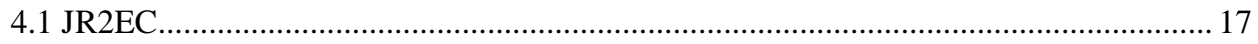

4.2 KE2C

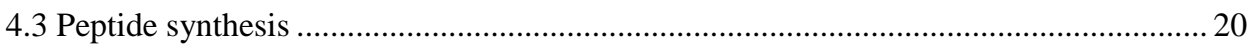

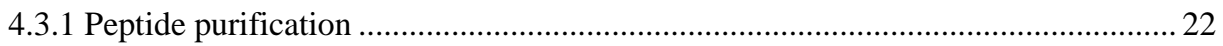

4.3.2 Peptide identification..................................................................................... 22

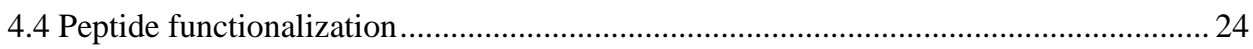

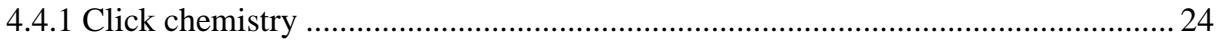

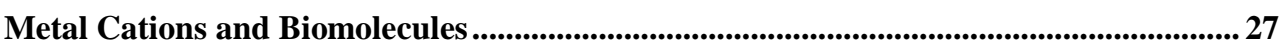

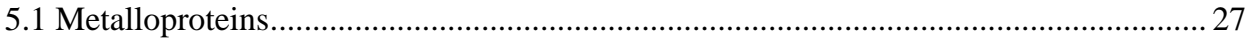

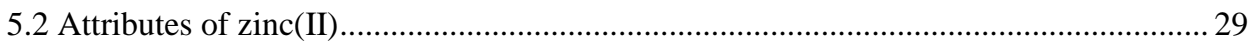

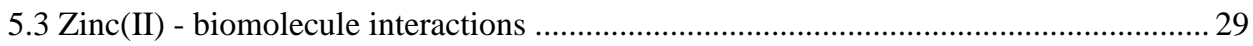

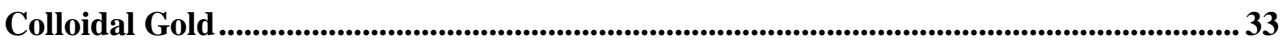

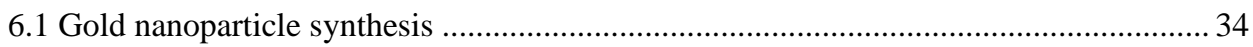

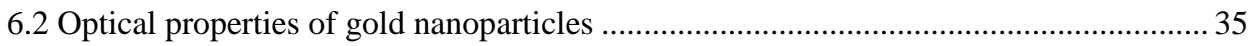

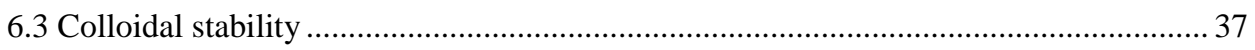

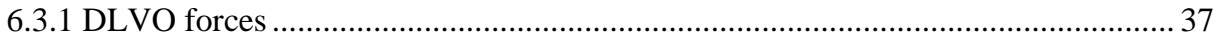

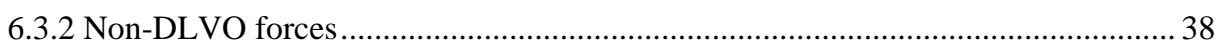

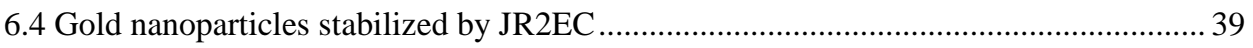

Polypeptide Functionalized Gold Nanoparticles ................................................................ 41

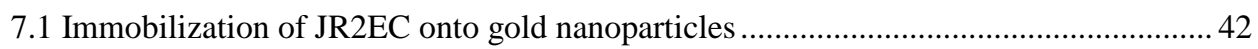

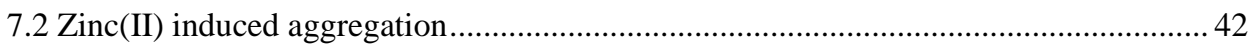

Gold Nanoparticles in Bioanalytical Applications .............................................................. 45

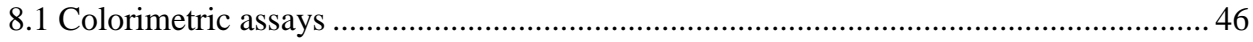

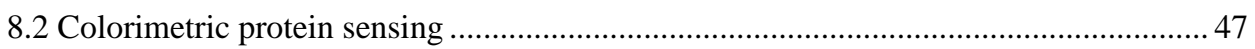

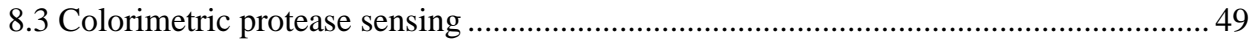

8.4 Colorimetric zinc-protein-chelant sensing ……………............................................. 49

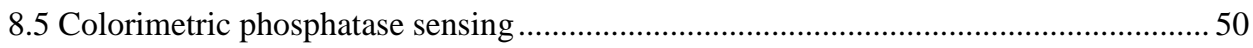

Summary of Papers................................................................................................................. 51

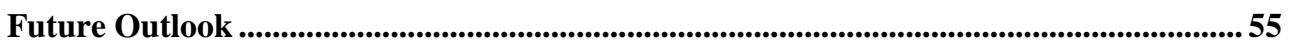

References ..................................................................................................................................... 57 


\section{CHAPTER 1}

\section{Introduction}

In 1959 Richard Feynman gave a now famous lecture where he envisioned a near-future where the entire 24 volumes of the Encyclopedia Britannica could be written on the head of a pin by manipulating mater at the nanoscale. ${ }^{1}$ This talk gave birth to the scientific area of nanotechnology but it took several decades before it came into focus and became the intense and flourishing research field it is today. Nanotechnology is a truly interdisciplinary field of science and encompasses chemistry, biology, physics, electronics and material science. It concerns the design, characterization and use of systems and devices in the size range of 1 100 nanometers where one nanometer is a billionth of a meter or $10^{-9}$ meters. Feynman accurately predicted that; "at the atomic level, we have new kinds of forces and new kinds of possibilities, new kinds of effects". ${ }^{1}$ Nanomaterials do indeed display unique physical, chemical, mechanical, and optical properties as compared to the corresponding macro-scale materials and these properties can be tuned as they scale with the size of the materials. ${ }^{2-3}$ Furthermore, forces that are less pronounced at the macro-scale can become dominant at this incomprehensibly small scale. These forces can, if the components constituting the nanomaterial are properly designed, be used to assemble novel and functional architectures with sub nanometer precision. This highly precise way to assemble nano-sized entities into larger functional structures is frequently occurring in nature and is fundamental to all aspects of life. Nature is thus a great source of inspiration for the field of nanotechnology as many of the assemblies found there involves nano-sized macrobiomolecules for which the assembly process has been perfected over millennia.

Nanomaterials are predicted to revolutionize electronics and materials science due to their many intriguing and novel properties. Many of these materials have also demonstrated interesting properties for sensing applications as they can be designed to be responsive to small alterations in their physicochemical surroundings and simultaneously provide mechanisms for transducing such effects into readily detectable signals. Nanomaterials are thus ideally suited for the sensing of macrobiomolecules as their presence or catalytic activity can influence the surrounding of the material in many different ways. Nanomaterials, and in particular functionalized nanoparticles, have consequently been extensively used for 
development of novel and highly sensitive detection strategies for important biomolecular analytes providing valuable assays for diagnostics and drug development. The nanoparticles can be designed to be responsive to a wide range of biomolecules including proteases, which can be disease markers for the common cold to cancers and ADIS, ${ }^{4-5}$ or to significantly smaller entities such as toxic metal ions. ${ }^{6}$ The assay response is most often but not always directly linked to the molecular recognition event. More flexible assays can be obtained by monitoring changes or species generated indirectly as a consequences of recognition. ${ }^{7}$ It is further possible to design detection schemes that not rely on the subtle changes in the physicochemical surrounding of the nanoparticle but instead changes its entire morphology as a response to biorecognition, enabling ultrasensitive detection of the analyte. ${ }^{8-9}$

The aim of the work presented in this thesis has been to explore the use of nanomaterialassembly as a means for sensing. The focus has been on how to use biomolecular forces, in particular polypeptide folding, to control the assembly process in a predictable and tunable manner. The assembly mechanisms have further been linked to the presence of certain biomolecular species to allow for their detection and characterization. Several different strategies for sensing have been explored for detection of a range of different targets, from small molecular chelants to enzymes and the fundamentally important processes they participate in.

The nano-sized material used throughout this thesis consists of gold nanoparticles functionalized with a $\mathrm{Zn}^{2+}$ responsive polypeptide. The polypeptide is designed to fold and dimerize and does so in the presence of $\mathrm{Zn}^{2+}$. Gold nanoparticles functionalized with this polypeptide can readily and reversibly be assembled by the addition of $\mathrm{Zn}^{2+}$ which yields dense aggregates with a well-defined interparticle distance. The unique optical properties of the gold nanoparticles allow for an easy assessment of the aggregates as the solution gradually changes color as a consequence of a decreased interparticle distance. Several fundamentally important biological processes that influence the particles directly or that affect the $\mathrm{Zn}^{2+}$ induced aggregation have been investigated in the included papers, I-IV. 
The following chapters are intended to put the work into a broader context and to provide an introduction to the nanomaterial used in the different papers. A schematic summary of the work presented in this thesis is illustrated in figure 1.1. In short: Chapter 2 gives an introduction to the field of bionanotechnology and the forces that can be used to assemble nanomaterials. Chapter 3 deals with protein and polypeptide composition, structure and folding. Chapter 4 describes polypeptide design, synthesis and functionalization. Chapter 5 concerns cations and their interactions with biomolecules with a focus on $\mathrm{Zn}^{2+}$. Chapter 6 deals with gold nanoparticle synthesis, colloidal stability and their unique optical properties. Chapter 7 describes how polypeptides can be immobilized on the surface of gold nanoparticles and how they can be used to control colloidal stability. Chapter 8 concerns bioanalytical sensing with a focus on colorimetric sensors.

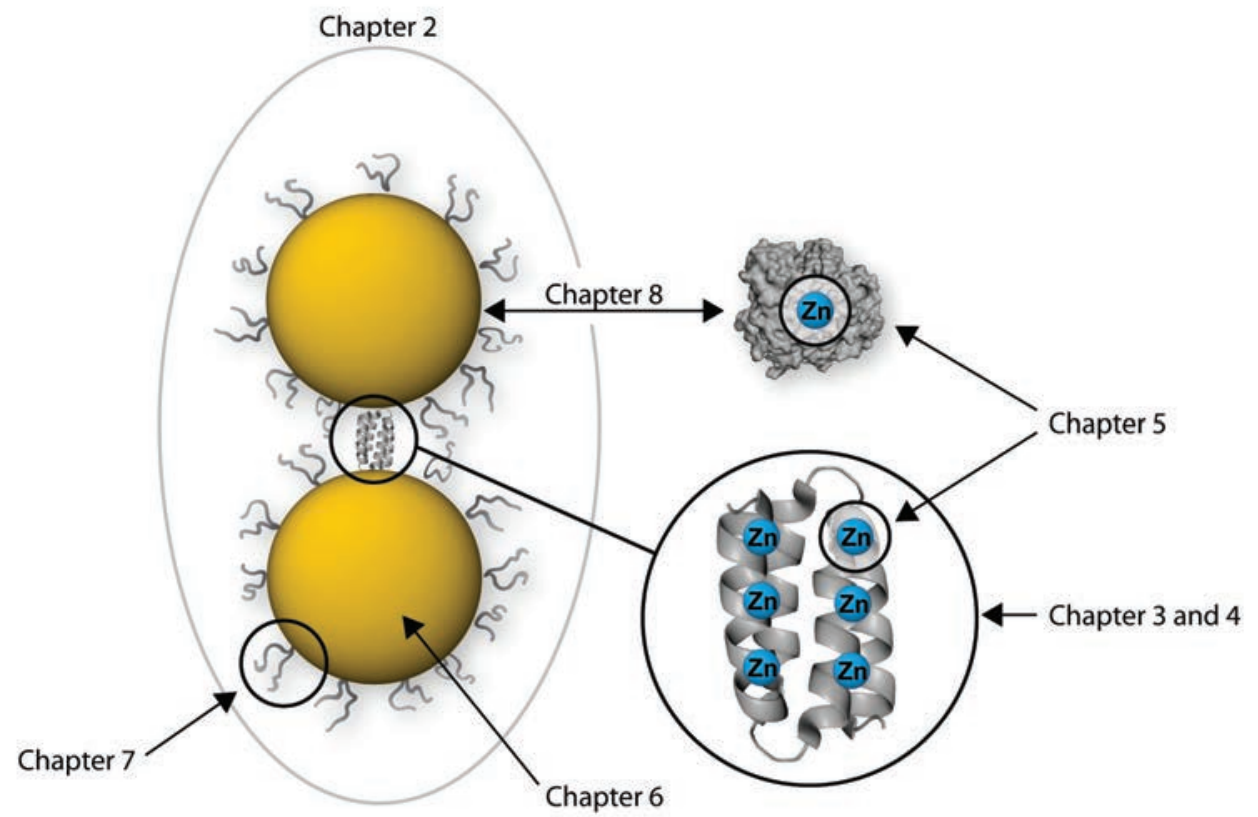

Figure 1.1 Schematic illustration of the outline of this thesis according to content of the chapters. 


\section{CHAPTER 2}

\section{Bionanotechnology and Self-Assembly}

This chapter provides a short introduction to bionanotechnology; the scientific area where nanotechnology and biology meet. It also describes the forces that can be used to assemble novel architectures using rather simple components.

\subsection{Supramolecular chemistry}

Supramolecular chemistry can be described as the association of two or more chemical species by solely intermolecular forces and hence differs from traditional chemistry which focuses on the covalent bond. Jean-Marie Lehn described supramolecular chemistry as "chemistry beyond the molecule" in his Noble lecture in $1988 .{ }^{10}$ As a distinct field of science it dates back to the 1960s but the concept of a "supermolecule" held together by non-covalent interaction predates even further and the term "Übermoleküle" was coined in the 1930s. ${ }^{11}$ Supramolecular interactions in nature are plentiful and inspirational, and are a necessity for life. Numerous of weak interactions govern biological functions such as protein-receptor substrate recognition, protein-protein assembly, cellular recognition, translation and transcription of DNA. The non-covalent forces at play can be divided into the following groups based on their different physical origin:

Electrostatic interactions: Is defined as a strictly Coulombic attraction or repulsion between two charge entities consisting of ions or dipoles. The electrostatic interaction can be further divide into sub-classes depending on the nature of the charges: ion-ion, ion-dipole and dipoledipole interactions ordered in declining binding strength. The interactions involving a dipole are orientation specific whereas the ion-ion is not. ${ }^{12}$

Hydrogen bonding: Is in its simplest form a specific type of a dipole-dipole interaction between a polarized hydrogen atom and an electronegative moiety, which most often is an atom. In supramolecular chemistry the hydrogen bond is of paramount importance, not just because of its strength, but for its different but defined directionalities. ${ }^{13}$

$\pi$-interactions: Similar to the electrostatic interactions a $\pi$-system generates a dipole moment that can interact with the face of another $\pi$-system $(\pi$ - $\pi$-interaction) or cation ( $\pi$-cation interaction) resulting in an attractive force. 
Van der Waals interactions: Fluctuations in the electron distribution of a molecule give rise to a temporary dipole which can polarize contiguous molecules to oscillate in union, creating a net attractive force. These forces are typically very weak and decline rapidly with distance but if the surface area is large these forces can become considerable. ${ }^{13}$

Hydrophobic effects: This force relates not to the interactions between the supramolecular components but rather to the solvation of them in an aqueous solution. ${ }^{\text {a }}$

These are the most predominant non-covalent forces that are utilized for the assembly of supramolecular architectures. Individually they may be too weak for the successful association of two chemical species but typically multiple interactions act in a concerted fashion, which can substantially improve the overall binding strength beyond the sum of its separate parts. This is referred to as cooperativity where two or more binding sites have a synergistic effect on the overall binding strength compared to when the binding sites act independently of each other. Another important factor is the complementarity of the chemical species both in terms of size and shape of the interaction sites but also with respect to the relative spatial arrangement the chemical moieties involved in the interactions. A high degree of complementarity also increases the selectivity, i.e. the discrimination between competing chemical species, allowing for a more predicable outcome which can be crucial in the assembly of supramolecular entities. ${ }^{12}$

Supramolecular chemistry can be divided into two major categories: host-guest chemistry and self-assembly. The distinction is typically based on the size of the involved chemical species. In host-quest chemistry, the larger of the two species is called "host" and envelopes the smaller "guest" species forming an inclusion complex. The biological equivalent could be the interaction between an enzyme (host) and its substrate (guest) or in terms of coordination chemistry a chelating agent and a metal ion. When the interacting species are of similar size and none of the species acts as a host for the other the association is referred to as selfassembly. $^{12}$

\subsection{Molecular self-assembly}

Molecular self-assembly is the spontaneous association of two or more chemical species into ordered structures and patterns without human intervention. ${ }^{14-15}$ The assembly process is directed by the chemically information encoded into the covalent framework of the individual components. If more than one type of interactions exists between the associating species a stepwise formation occurs with the optimization of the most stabilizing interaction first. ${ }^{12}$

\footnotetext{
${ }^{\mathrm{a}}$ The hydrophobic effect is described in more detail in chapter 3.1 which concerns protein folding.
} 
Since supramolecular systems are held together by non-covalent interactions they are inherently dynamic, allowing for rearrangement of components to form the most thermodynamically stable structure. This is an important feature as "mistakes" can be corrected. It also means that if the reaction conditions are altered the equilibrium of the system may shift, favoring the individual chemical species as the most thermodynamic stable product, resulting in a disassembly of the unstable architecture. ${ }^{14-15}$ Self-assembly offers a general strategy for the fabrication of ordered nanostructures from relatively simple components.

\subsection{Nanotechnology and bionanotechnology}

Nanotechnology was defined by the Royal society in 2004 as the "design, characterization, production and application of structures, devices and systems by controlling shape and size at nanometre scale". ${ }^{3}$ If nanoscience is the study of the properties arising from these materials then nanotechnology is the exploitation of them in various applications. Nanotechnology has a huge potential in the development of stronger and lighter materials as well as miniaturization of electronics etc. However by observing Nature, the true power of nanomaterials can be realized; with its spectacular supramolecular nanoscale machines and architectures spontaneously constructed from smaller entities by self-assembly. ${ }^{16}$ One example is the arrangement of the two different proteins forming the virus capsid of the tobacco mosaic virus. The capsid takes the shape of a protecting cylindrical vessel that envelope the RNA. It is formed by the self-assembly of precisely 2130 coat-proteins in a well-defined pattern that is encoded by the supramolecular interactions involved. ${ }^{17-18}$ Another striking example is the ATP synthase protein complex, which is composed of several proteins associated by noncovalent forces forming not only one, but two rotary motors, where the second one works in reverse. The first motor utilizes the hydrogen gradient of the mitochondria to rotate, transferring the rotational energy into the second motor, forcing it to go backwards hence creating a generator which produces chemical energy for the cell in the form of ATP. ${ }^{19}$ This is where the field of bionanotechnology finds its inspiration.

Bionanotechnology is the field of science where nanotechnology and biology meet and aims at the development of devices and materials for e.g. sensors, drug delivery and tissue engineering applications. Many of the molecular components used are directly adopted from a biological context or designed with inspiration from the structure and function of biomolecules. Molecular self-assembly is a truly interdisciplinary field of science where biology, chemistry and physics converge in order to decipher and use the forces that govern 
the assemblies in a controllable and predictable way. Molecular self-assembly has emerged as a very attractive route for bottom-up ${ }^{\mathrm{a}}$ fabrication of nanomaterials.

Several astonishing steps have already been taken using both proteins and DNA as templates in the construction of nanomaterials. The specific base pairing in DNA makes it a suitable molecular component for self-assembly as the specificity offers a route for achieving a predictable and tunable outcome of the assembly process, i.e. programmability. ${ }^{20}$ The programmability in combination with well-established protocols for synthesis of oligonucleotides has facilitated the realization of a range of DNA-based nanostructures such as rotary DNA nanomachines, ${ }^{21}$ and DNA arrays, ${ }^{22}$ and have led to the development of the field called DNA origami. In DNA origami $2-\mathrm{D},{ }^{23}$ and 3-D DNA architectures are fabricated, ${ }^{24}$ that indeed can be functional. One intriguing example is a 7000 nucleotides long single stranded DNA sequence that self assembles into a nano-sized box with a lid that can be opened when a DNA strand complimentary to the "lock" of the lid is added. ${ }^{25}$ DNA can also be combined with other nano-sized components such as nanoparticles resulting in so called spherical nucleic acid (SNA) where the highly specific recognition of a complementary strand is retained, which in turn can be used to control the specific assembly of the SNAs. ${ }^{26-27}$

Proteins are, with respect to composition, significantly more complex than DNA, and do not possess the same obvious programmability. They are on the other hand more versatile in their structures and functions. ${ }^{\mathrm{b}}$ Proteins are extensively used in biosensors because of their ability to selectively recognize other proteins and organic molecules. This recognition attribute, found in for example receptors and antibodies, can also be used to trigger nanoparticle assembly. ${ }^{28-29}$ Proteins are typically not very robust and may irreversibly lose their native structure and hence functionality because of changes in their physicochemical environment, such as increasing temperature, drying, high or low $\mathrm{pH}$, or in the presence of a solid substrate. However, shorter sequences of amino acids, so called peptides, can provide a more robust option to proteins that also can be produced synthetically. Peptides can be designed to adopt secondary structures and structural motifs similar to proteins but are less sensitive to changes in their surroundings since any unfolding is typically reversible. ${ }^{30-31}$ As they are chemically synthesized non-natural species can be readily introduced making them even more versatile and flexible. ${ }^{32}$ Peptides have been used in numerous interesting applications, including assembly of supramolecular nanofibers, ${ }^{33}$ responsive hydrogels, ${ }^{34}$ nanotubes, ${ }^{35}$ and for assembly of nanoparticles. ${ }^{36-37}$

\footnotetext{
a Bottom up was defined by the Royal society as "involves the assembly of smaller sub-units (atoms or molecules) to make a larger structure" in contrast to the top-down approach which was defined as "starting with a block material, and etching or milling it down to desired shape". 3

${ }^{\mathrm{b}}$ A more in-depth description of the composition and structure of proteins can be found in chapter 3 .
} 


\subsection{Nanocomposites and hybrid nanomaterials}

The combination of organic and inorganic components led to the development of composites materials in the mid- $20^{\text {th }}$ century. These materials showed new and improved properties not necessarily found in either of the starting materials. Composite materials are often based on a polymer (organic) which forms the matrix around micrometer sized inorganic components. ${ }^{38}$ The constituents are chosen and combined to accentuate the desired properties and to diminish the unwanted once to make materials that are lighter, stronger and more flexible as compared to the starting materials. Synthetic composites often fall flat when compared to those found in nature, which are not only ordered at the micro level but through the entire size range from nano to meso. ${ }^{39}$ This gives the natural occurring composites found in for example shell, bone and teeth mechanical properties not accessible via traditional synthesis-strategies. Additionally, most natural occurring composites are multi-functional. Bone for example, consists of a mixture of calciumphosphate ${ }^{a}$ and collagen and does not only act as a support for the body but also provides a site for blood cell formation. As the size of both the organic and inorganic components decrease, the surface to volume ratio increases dramatically and the interface between the constituents becomes more and more important and starts to define the material. ${ }^{40}$ The forces connecting the components can either be of a strong covalent nature or in the form of weak supramolecular interactions. ${ }^{41}$ Composites joined by supramolecular forces may display properties such as self-healing due to the reversibility of interaction taking place at the interfaces. This is a common trait in natural occurring composites where the components are in the size range of approximately $<50 \mathrm{~nm}$ and often held together by noncovalent interactions. ${ }^{39}$ Synthetic composites that consists of nano-sized components have also been realized and are utilized in for example contrast agents, ${ }^{42}$ smart coatings, ${ }^{41}$ and biosensors. $^{43}$ These materials can broadly be divided in two sub categories: nanocomposites and hybrid nanomaterials. In nanocomposites at least one of the components, either the organic or inorganic, is in a defined size range in the order of nanometers, or has components that is continuously repeated with a separation in the nanometer range, ${ }^{44}$ whereas in hybrid nanomaterial all components are nanosized. ${ }^{45}$ The border between these definitions is however fluid and they are often used interchangeably. Several suitable build blocks can be used as the inorganic component such as metallic nanoparticles, nanoparticles of semiconductors (quantum dots) and nano-sized flakes of clay. The organic component can be a polymer but also a biomolecule such as DNA, protein or peptide. ${ }^{40,46-47}$ In this thesis a hybrid nanomaterial is extensively used where polypeptides are combined with metal nanoparticles.

${ }^{\mathrm{a}}\left[\mathrm{Ca}_{3}\left(\mathrm{PO}_{4}\right)_{2}\right]$ 
CHAPTER 3

Structure of Proteins and Protein Folding

Proteins are a class of biomolecules with a fundamental importance in biological systems. They have numerous critical roles in the cell and its surroundings, from the catalytically tasks of the enzymes to the protective role of the antibody. No other group of biomolecules is as versatile and spectacular in its rather simple yet ingenious design. All proteins are essentially linear heteropolymers, constructed from a library of twenty different amino acids covalently linked to a continuous polymer chain with a specific sequence and three dimensional structure. The linkage between individual amino acids is called the amide bond or peptide bond and is formed by a condensation reaction between the carboxylic acid group of one amino acid and the amino group of the next one, forming a linear polymer denoted as a polypeptide chain (Figure 3.1). During the formation of the amide bond one molecule of water is released for each linkage formed and the remaining part of the condensed amino acid is hence called a residue.

The amide bond exhibits some special features because of the overlap between lone pair of the nitrogen and the carbonyl $\pi$-bond, giving it a double bond character. This makes the amide bond length shorter and imposes restrictions on the rotation compared to an $\sigma$-bond, locking it in a planar conformation either as trans or cis isomer at physiological conditions. In proteins the trans form is dominant since it its energetically more favorable but the cis form does occur on rare occasions. ${ }^{48}$ Even though the peptide bond increases the rigidness of the backbone, the polymer can still rotate around the bonds connecting the $\alpha$-carbon and the rotation is defined by the dihedral angles (Phi, $\Phi$ and Psi, $\Psi$, Figure 3.1).

There are essentially only two factors that differentiate proteins from each other: the number and composition of amino acids. The number of amino acids in a protein varies widely where the largest consists of several thousand amino acid residues but a more commonly occurring size is 200-500 residues. ${ }^{49}$ 


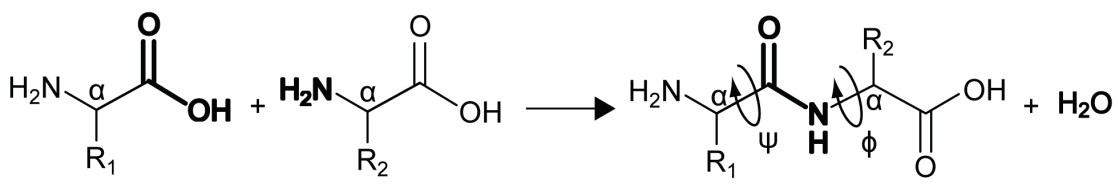

Figure 3.1 Formation of a dipeptide by covalently linking two amino acids by the reaction of a carboxylic acid and an amine functionality producing a water molecule as a byproduct. The chemical properties of individual amino acids are defined by their R-groups $\left(\mathrm{R}_{\mathrm{x}}\right)$ and are situated on the $\alpha$-carbon. Dihedral angles (Phi, $\Phi$ and Psi, $\Psi)$ define the conformation of the polypeptide backbone whereas the amide bond constitutes a more rigid part of the backbone.

The other main factor that differentiates proteins from each other is the types and order of the amino acids. There are twenty natural occurring amino acids with different chemical properties defined by their R-group situated on the $\alpha$-carbon (Figure 3.1). They can be divided into three main groups based on these properties; charged, polar and non-polar. It is the precise sequence of these chemical properties that encodes for structure and function of each individual protein and is denoted as its primary structure. The possible combinations are infinite and far from all lead to a protein with a defined structure and function.

The polypeptide backbone can adopt localized and defined structural conformations as a direct consequence of its amino acid sequence. This overall increase in structural order is called secondary structure. Two main types of secondary structure exist, the parallel alignment of the polypeptide backbone termed $\beta$-sheet and a spiral arrangement termed $\alpha$ helix (Figure 3.2). Both types are stabilized by hydrogen bonds in the main chain and leads to a segment of the backbone with a common set of $\Psi$ and $\Phi$ angles. The lack of a secondary structure is referred to as a random coil.

The $\Psi$ and $\Phi$ angles in a $\beta$-strand are typically fully extended giving it a conformation that is not stable on its own but requires additional stabilization. This is achieved by aligning several $\beta$-strands into a sheet allowing for an extensive hydrogen bonding network between the backbone carbonyl $(\mathrm{C}=\mathrm{O})$ of one amino acid residue with the amino group $(\mathrm{N}-\mathrm{H})$ on an adjoining strand (Figure 3.2a). The alignment of the individual strands can be parallel or antiparallel with respect to the direction of the primary structure of the flanking strand. The $\beta$ sheet can be composed of segments distant from each other in the primary structure or even from separate proteins. ${ }^{49}$

The $\alpha$-helix in contrast to the $\beta$-sheet is an isolated structure with intramolecular interactions that may support its own structural conformation although a single $\alpha$-helix is typically only marginally stable. The spiral pattern of the backbone is achieved when a stretch of consecutive amino acid residues have $\Psi$ and $\Phi$ angles of approximately $-50^{\circ}$ and $-60^{\circ}$, 
respectively. The ideal $\alpha$-helix has 3.6 amino acids per turn extending it $5.4 \AA$ for each complete consecutive gyration. The polypeptide backbone of the $\alpha$-helix is closely packed allowing for favorable van der Waals interactions within its interior. The R-groups are projected outwards from the helical backbone, minimizing interfering sterical interactions. The polar amide groups are neutralized by hydrogen bonding as they otherwise would be an unfavorable factor in the hydrophobic interior of the helix. The carbonyl group in each residue in the $\alpha$-helix forms hydrogen bonds with the amino group $n+4$ aligning the dipole moment of the hydrogen bond along the axis of the helix, resulting in a significant net dipole moment. Many $\alpha$-helixes are amphiphilic with non-polar R-groups at one face of the helix and polar or charged R-groups in other positions. The resulting coherent hydrophobic surface propels the helix to associate with a similar helix or with another non polar surface to minimize its exposure to the aqueous environment. Two helixes associated in this manner is said to form a motif which is a level of organization between the individual secondary structure elements and the tertiary structure of a domain that may comprises the entire folded state of a protein.

a)

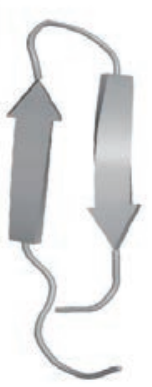

b)

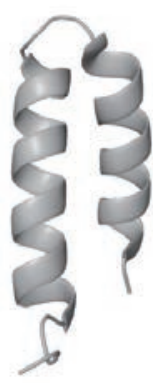

c)

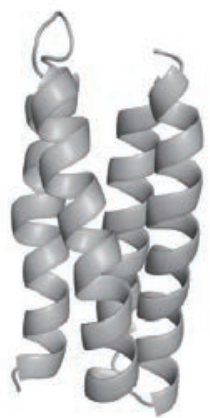

Figure 3.2 Secondary structural motifs a) two strands forming a $\beta$-sheet (PDB entry $1 \mathrm{ZY} 6^{50}$ ). b) A helix-loophelix motif consisting of two $\alpha$-helixes joined by a loop region (PDB entry $2 \mathrm{GP}^{51}$ ). c) A four-helix bundle consisting of two associated helix-loop-helix motifs forming a tertiary structure (PDB entry 2JUA ${ }^{52}$ ). Structures were acquired from the protein data bank $(\mathrm{PDB})^{53}$ and visualized using polyview. ${ }^{54}$

A helix-loop-helix motif is significantly more stable than an isolated helix being comprised of two helixes parallel aligned and joined by an unstructured loop region (Figure 3.2b). The most common helical tertiary structure is the four-helix bundle, composed of four amphiphilical $\alpha$ helices that form a tightly packed structure with almost parallel arrangement of the helixes, effectively hiding any hydrophopic residues from the surrounding water (Figure 3.2c). It may be comprised of four isolated helix segments from the polypeptide backbone or from the association of motifs such as two helix-loop-helix motifs. ${ }^{55}$ 


\subsection{Protein folding}

From a thermodynamic point of view, the process of protein folding can be described as an energy landscape with the shape of a course funnel where the depth and width of the funnel corresponds to the enthalpy $(\Delta \mathrm{H})$ and entropy $(\Delta \mathrm{S})$ of the system, respectively. ${ }^{56}$ At the initial phase the polypeptide chain exists as a random coil situated at the top of the funnel with high entropy due to its large number of random conformational states. As the protein folds and progresses down through the funnel it passes several discrete structural conformations called molten globules characterized by an almost intact secondary structure but lacking the final native like arrangement of these structural elements. As the protein folds into its native state the tertiary arrangement of secondary structure are finalized as a dense structure situated at the bottom of funnel, corresponding to the lowest enthalpy.

The forces that govern protein folding are essentially the same as those involved in formation of supramolecular assemblies ${ }^{\mathrm{a}}$ and it is the sum of these interactions that determines the overall stability of the native folded state. A polypeptide chain existing as a random coil possesses a high conformational entropy due to its nearly infinite number of possible conformations arising from rotations around single bonds. Folding of the polypeptide main chain creates a rigid structure decreasing the conformational entropy and this loss must hence be compensated for. Favorable interactions such as van der Walls and electrostatic interactions as well as intramolecular hydrogen bonding in the folded state partly compensate by increasing the enthalpy of the system. It is however not only thermodynamics of the protein that needs to be considered but also that of the surrounding solvent. The solvatisation of an unstructured polypeptide chain in aqueous solution forces water molecules to adopt an order network around hydrophobic residues, which decreases the conformational entropy of the solvent. Folding and burial of these residues in the structural elements of the protein releases the water molecules compensating for some of the lost entropy related to the decreased conformational freedom in the native state. This effect is commonly denoted as the hydrophobic effect and is a key element in the thermodynamics of protein folding. ${ }^{48}$

Due to the trade of between enthalpy and entropy, described by equation 3.1 the native state is only marginally stable with a Gibbs free energy $(\Delta \mathrm{G})$ difference of 5-15 $\mathrm{kcalmol}^{-1}$ corresponding to about three hydrogen bonds at physiological conditions. ${ }^{55}$

$\Delta G=\Delta H-T \Delta S$

\footnotetext{
${ }^{\mathrm{a}}$ Forces that govern supramolecular assemblies are described in chapter 2.
} 


\subsection{Circular dichroism spectroscopy}

The structure of a protein can be determined by several methods where nuclear magnetic resonance (NMR) spectroscopy and X-ray crystallography give structural data at the highest resolution. However, these methods are very time consuming and complicated to perform. Circular dichroism (CD) spectroscopy gives less information but is on the other hand rapidly performed and often used for peptide and protein secondary structure characterization. ${ }^{57-59}$ In CD spectroscopy the sample is irradiated with circularly polarized light and the difference in absorption of the left- and right-handed circularly polarized components is detected. Optically active or chiral entities such as the amide bond in a polypeptide backbone absorb these components to different extents depending on the two dihedral angles $\phi$ and $\psi$. Absorption by the amide bond occurs in the far-UV region, below $240 \mathrm{~nm}$, and can be used to identify the secondary structure elements of the polypeptide as each such element gives a characteristic spectrum. The spectrum of $\beta$-sheet has a minimum at $216 \mathrm{~nm}$ and a maximum at $195 \mathrm{~nm}$, an $\alpha$-helix has two pronounced minima at 208 and $222 \mathrm{~nm}$ and a maximum at $190 \mathrm{~nm}$ whereas a random coil has a minimum at $198 \mathrm{~nm}$ (Figure 3.3).

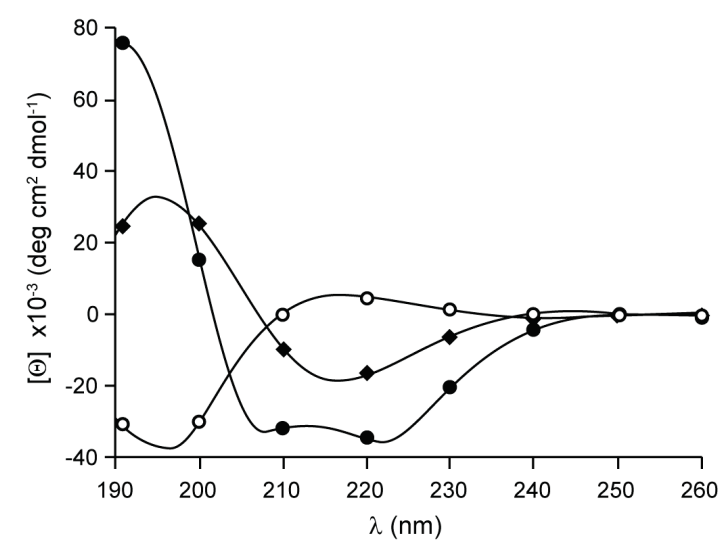

Figure 3.3 CD-spectra in the far-UV region of a $\beta$-sheet $(\bullet)$, an $\alpha$-helix $(\bullet)$ and a random coil (०). 
Two components (right- (R) and left-handed (L) polarized light) have unequal extinction coefficients $(\varepsilon)$, the difference $(\Delta \varepsilon)$ is related to the difference in absorption $(\Delta A)$ of the two components according to the Lambert-Beer relation:

$\Delta A=l * c * \Delta \varepsilon$

where $l$ is the optical path length and $c$ is the concentration of the sample. As the two components of the incident light are absorbed to different extents, the observed light becomes elliptically polarized. CD is thus described in terms of elliptictiy $(\Theta)$ which is the angle between the major and minor axis of the ellipse defined by the vector sum of the $\mathrm{R}$ and $\mathrm{L}$ components. $\mathrm{CD}$ is measured as a function of wavelength and $\Delta A$ is related to $\Theta$ for each wavelength according to:

$\Theta=\frac{\ln 10 * 180 * \Delta A}{4 \pi} \approx 33 * \Delta A$

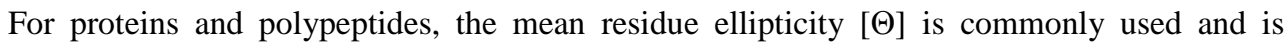
related to $\Theta$ according to:

$[\Theta]=\frac{\Theta * m r w}{10 * l * c}$

where $m r w$ is the mean residue weight of the amino acids constituting the polypeptide or protein in $\mathrm{g} / \mathrm{mol}, l$ is the optical path length in $\mathrm{cm}$ and $c$ is the concentration in $\mathrm{g} / \mathrm{ml}$. 


\section{CHAPTER 4}

\section{Synthetic Peptides}

Synthetic polypeptides can fully or partly be based on natural occurring motifs or be de novo designed, having no natural precursor. The last alternative allows for the synthesis of peptides with new functions and properties not necessarily found in nature and have become a reality as increasing insights to the rules that govern protein folding have been unraveled. It is now possible to design de novo peptides that adopt an ordered secondary structure such as $\beta$ sheets, ${ }^{34,60}$ or $\alpha$-helices when the peptide is free in solution ${ }^{61}$. It is also possible to design polypeptides that folds into a helical structure as a result of an interaction with a surface, ${ }^{62-63}$ or with a complimentary peptide. ${ }^{30,64}$ Alternatively, helices can be formed in response to external stimuli such as change of $\mathrm{pH}^{36}$ change of temperature, ${ }^{65}$ or the presence of metal cations. ${ }^{66-67}$ In this thesis de novo designed polypeptides are utilized in all papers.

\subsection{JR2EC}

The 42 amino acid synthetic polypeptide JR2EC used in this thesis belongs to a family of helix-loop-helix polypeptides de novo designed by Lars Baltzer et al. and dimerizes into antiparallel four-helix bundles in the presence of a charge-complementary peptide (Figure 4.1a). JR2EC was originally designed by Johan Rydberg and Sarojini Vijayalekshmi and further refined by Karin Enander and Daniel Aili who introduced a cysteine residue in its loop region to allow for immobilization onto gold substrates. ${ }^{30,64}$ The structure of JR2EC in its folded state can be visualized by utilizing a heptad repeat (abcdefg) pattern $^{\mathrm{a}}$, where each letter corresponds to an amino acid position in the final fold (Figure 4.1b). Since an $\alpha$-helix has 3.6 amino acids per turn the incorporation of a specific amino acid at approximately every fourth position will create a face running along the entire cylindrical length of the helix and the chemical nature of this face will be determined by the properties of the chosen amino acid. This principle was exploited in the design of JR2EC.

\footnotetext{
${ }^{\text {a }}$ Also commonly referred to as a helical wheel representation.
} 
a)

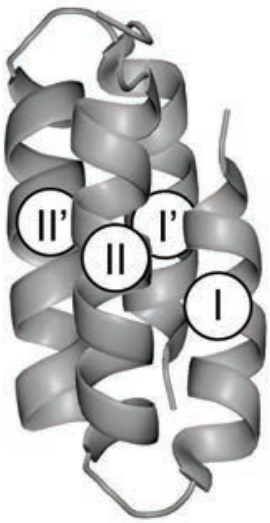

b)
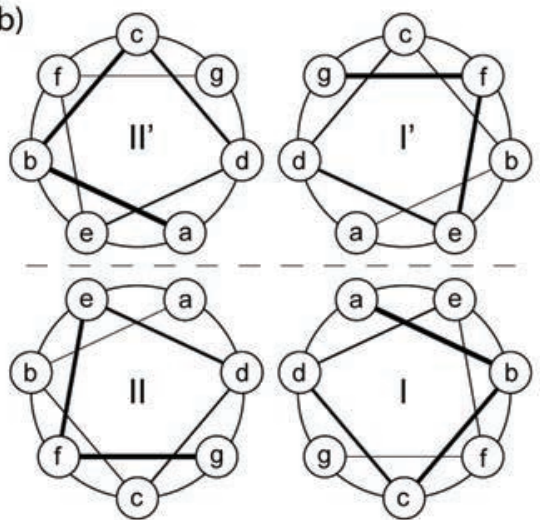

c)

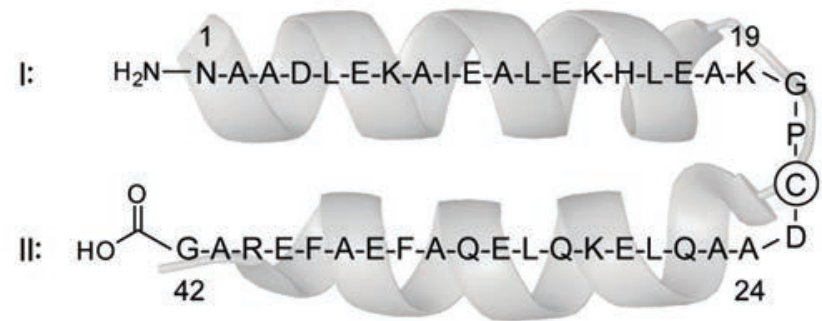

Figure 4.1 a) Four-helix bundle with an antiparallel alignment. b) The heptad repeat pattern is illustrated as a top-down view of the antiparallel four-helix bundle and couples the primary structure of the individual polypeptides to the tertiary structure of the final fold. The dashed line represents the dimer interface between the two helix-loop-helix motifs. c) Primary structure of JR2EC. Figure b) redrawn from ${ }^{68}$.

In the $a$ and $d$ positions hydrophobic residues such as Ala, Leu and Ile were chosen. These residues form the hydrophobic core of the four helix bundle, the formation of which is a key driving force in the folding of the peptide. Residues in positions $b$ and $e$ make up the interface between monomers and are predominantly Glu, while hydrophilic residues in the $c$ and $g$ positions create the solvent exposed face. The primary structure of JR2EC is shown in figure 4.1c.

Due to the high $\mathrm{Glu}^{\mathrm{a}}$ content of the peptide it has a net charge of -5 at neutral $\mathrm{pH}$ and charge repulsion effectively prevents dimerization and folding. By lowering $\mathrm{pH}$ below 6, these charged residues become protonated and the polypeptide rapidly homodimerizes and folds (Figure 4.2a). Folding can also be induced at neutral $\mathrm{pH}$ by introducing a complementary peptide termed JR2KC that is identical to JR2EC in its primary structure except that all Glu residues have been exchanged for Lys. JR2KC exhibits a net charge of +11 at neutral $\mathrm{pH}$ and is hence complementary in terms of charge towards JR2EC. The mixture of these two peptides in a 1:1 stoichiometric relationship leads to heterodimerization and folding with a

\footnotetext{
${ }^{\text {a }}$ The one letter abbreviation for Glu is E.
} 
dissociation constant of $20 \mu \mathrm{M}$, according to a circular dichroism spectroscopy analysis. ${ }^{64}$ The complex formation has been further characterized by ultracentrifugation as well as NMR spectroscopy. ${ }^{30}$ The utilization of JR2EC and JR2KC for fiber formation but also to assemble nanoparticles is described in more detail elsewhere. ${ }^{69}$ Neither of these strategies was used in this thesis, instead a third possibility was employed which relies on the homodimerization of JR2EC induced by metal cations. Several di- and tri-valent metal cations had previously been demonstrated to induce folding and dimerization of JR2EC at neutral $\mathrm{pH}$ (Figure $4.2 \mathrm{~b}$ ). ${ }^{37}$ Of these species $\mathrm{Zn}^{2+}$ was found to induce the highest degree of helicity and was utilized for this purpose in papers I, III and IV. However, not all metal cations induce folding of JR2EC, including the common enzymatic cofactors $\mathrm{Mg}^{2+}$ and $\mathrm{Ca}^{2+}$. This tendency to discriminate between cations and still be responsive to $\mathrm{Zn}^{2+}$ is an important feature in paper IV.

The polypeptide JR2EC contains a cysteine residue which acts as a chemical handle that can be utilized for site specific and direct thiol-dependent immobilization on gold substrates. This residue is positioned in the loop region of the helix-loop-helix motif in order to minimize its effect on the dimerization properties of the polypeptide when immobilized (Figure 4.1c). This immobilization strategy was utilized in all papers for functionalization of both gold nanoparticles in papers I-IV and planar gold surfaces in papers I-II.

a)

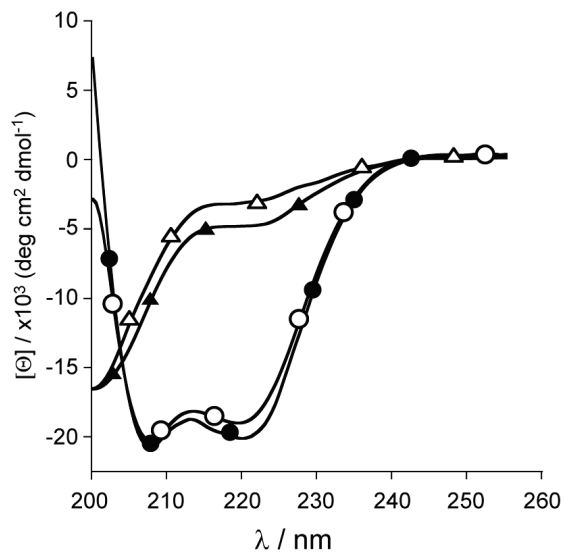

b)

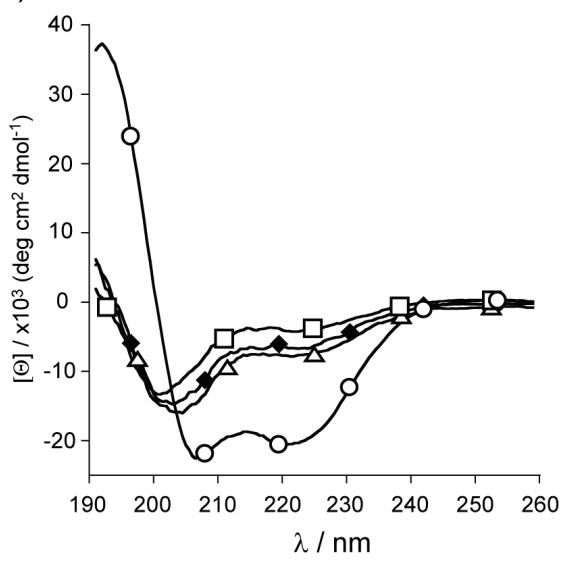

Figure 4.2 a) CD-spectra of JR2EC $(\boldsymbol{\Delta})$ and JR2KC $(\Delta)$ at $\mathrm{pH} 7$, where both polypeptides reside as random coil monomers. The mixture of JR2EC and JR2KC (o) at $\mathrm{pH} 7$ leads to heterodimerization and folding into a fourhelix bundle. Homodimerization of JR2EC as a result of exposure to a pH of $4.5(\bullet)$. b) Homodimerization of JR2EC can also be induced by $\mathrm{Zn}^{2+}(\circ)$ whereas $\mathrm{Mg}^{2+}(\diamond)$ and $\mathrm{Ca}^{2+}(\Delta)$ fail to induce folding and are comparable to buffer only $(\square)$. Figures redrawn from ${ }^{69}$. 


\subsection{KE2C}

In paper I a synthetic receptor was utilized which binds the metalloenzyme human carbonic anhydrase II (HCA II). This receptor was design by Karin Enander and consists of a polypeptide termed KE2C which is post-synthetically modified with a benzenesulphonamide derivative (C6), ${ }^{a}$ an inhibitor of HCA II (Figure 4.3). ${ }^{70-71}$ Similar to JR2EC, this helix-loophelix peptide is 42 amino acids in length and was designed to homodimerize and fold into a four-helix bundle. At neutral $\mathrm{pH}$, it has a net change of -0.9 , implying considerably less charge respulsion than in JR2EC, and can consequently homodimerize. This polypeptide was originally used in biosensor applications and did at that point also contain a fluorescent reporter group which could convey the binding of HCA II as an optical signal. This combined recognition and reporting system was further elaborated by varying the benzenesulphonamide derivative, tailoring the affinity towards HCA II in order to create an affinity array. ${ }^{32}$ In this thesis the polypeptide-benzenesulphonamide receptor with the highest affinity towards HCA II was utilized, but the fluorescent reporter group was omitted. KE2C was tethered to gold nanoparticles via the cysteine residue in the loop region as a recognition element in paper I.

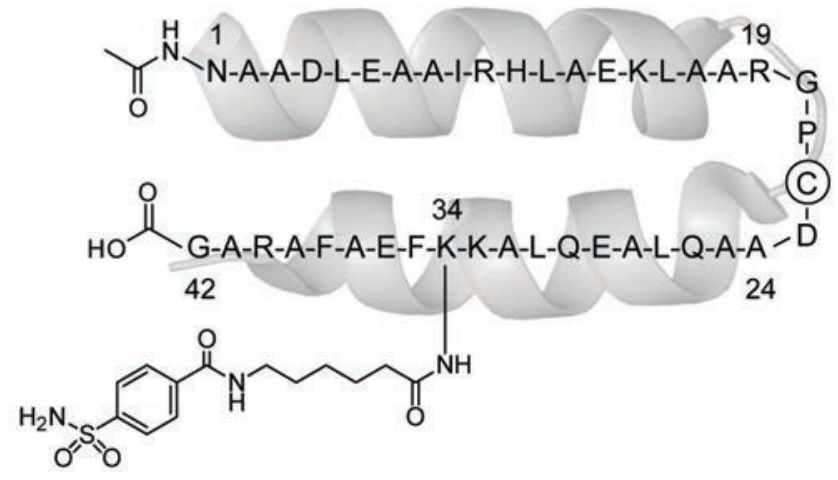

Figure 4.3 Primary structure of KE2C-C6 with a benzenesulphonamide derivate conjugated to the Lys residue in position 34.

\subsection{Peptide synthesis}

Solid phase peptide synthesis (SPPS) was introduced in 1963 by Merrifield et al. ${ }^{72}$ In SPPS the C-terminal amino acid is anchored to an insoluble solid support and the peptide is elongated by the sequential coupling of activated amino acids. This approach allows for the convenient removal of soluble by-products as well as excess reagents by filtration without the loss of peptide as it is tethered to the solid support. SPPS was rapidly automated by Merrifield after its invention increasing its utility even further with higher yields and shorter synthesis

\footnotetext{
${ }^{\text {a }}$ A more in-depth description of post-synthetically modifications is given in chapter 4.4. 
time $^{73}$ This technique is not limited to the synthesis of linear polypeptides as branched as well as circular peptides may be produced, consisting of both natural and unnatural amino acids. ${ }^{74}$ Vast combinatorial libraries have also been synthesized using this technique. ${ }^{75}$ The upper limit for SPPS is about 100 amino acids with the limiting factor being the yield in each coupling step. ${ }^{76}$ The yield normally exceeds $99 \%$ but when very long peptides are synthesized erroneous sequences rapidly accumulate. This problem can however be circumvented by employing ligation techniques that allow for conjugation of separate peptide segments into full length proteins. ${ }^{77-78}$

In SPPS polystyrene beads cross-linked with a low degree of divinylbenzene is often employed as the solid support. ${ }^{72}$ The beads are further functionalized with linkers that can anchor the C-terminal amino acid to the support. The low degree of cross-linking allows the polymer to swell and accommodate the growing peptide as well as allow for rapid diffusion of reagents throughout the entire bead.

Both the $\alpha$-amino group and reactive side chains need to be protected during the coupling steps in order to avoid uncontrolled polymerization of the amino acids. The $\alpha$-amino group can be protected either with an Fmoc ${ }^{\text {a }}$ group, which can be removed by a mild base such as piperidine or morpholine, or a Boc ${ }^{b}$ group, which can be removed by a strong acid such as TFA. In this thesis an Fmoc based protection strategy has been exclusively employed. Protection of reactive side groups can be achieved by a large number of different protection groups but they usually have in common that they can be removed simultaneously as the polypeptide is cleaved from the solid support.

The cyclic approach of SPPS is described in Figure 4.4 where the first amino acid is initially attached to the solid support via a linker. Fmoc deprotection makes the $\alpha$-amino group accessible for peptide elongation. The $\alpha$-carboxylic group of the second amino acid is activated for efficient coupling. In this thesis $\mathrm{TBTU}^{\mathrm{c}}$ in combination with the base DIPEA ${ }^{\mathrm{d}}$ was used as activating reagents, however a large number of different activator reagents are available. A large excess of the activated amino acid is then used to drive the reaction to completion and unreacted reagents can then be removed by washing. The cyclic procedure with Fmoc removal and subsequent coupling is then repeated until the last amino acid has been attached. The N-terminus can then be either acetylated with acetic anhydride as in KE2C or left as an amine group as in JR2EC. The final polypeptide is then deprotected and

\footnotetext{
${ }^{\text {a }}$ Fluorenylmethyloxycarbonyl

b Tert-butyloxycarbonyl

c $O$-(7-benzotriazole-1-yl)-1,1,3,3-tetramethyluronium tetrafluoroborate

${ }^{\mathrm{d}}$ Diisopropylethylamine
} 
cleaved from the solid support by treatment with trifluoroacetic acid (TFA). Cleavage can yield either a carboxyl acid or an amide functionality in the C-terminus depending on the linker used. During cleavage scavengers such as trisiopropylsilane (TIS) are added to trap reactive species released during side chain deprotection preventing them from undergoing unwanted side-reactions with the polypeptide. After cleavage the solid support is removed by filtration and the TFA is evaporated. The crude polypeptide is then precipitated in cold ether, resuspended and lyophilized.

\subsubsection{Peptide purification}

Purification of the crude polypeptide is conventionally performed using reversed phase highperformance liquid chromatography (RP-HPLC). In this technique a hydrophobic stationary phase is used, commonly consisting of hydrocarbon functionalized silica particles. A polar solvent, usually a mixture of water and acetonitrile, isopropanol or methanol is commonly used. The solvated polypeptide is passed through the stationary phase and depending on the polarity of the polypeptide it will interact more or less with stationary phase and elude accordingly. HPLC can be coupled to several detection techniques. UV detection was used in this thesis as the amide bonds of the polypeptide main chain can absorb light at around 230 $\mathrm{nm}$.

\subsubsection{Peptide identification}

The identification of the polypeptide was performed using matrix-assisted laser desorption ionization time of flight mass spectrometry (MALDI-TOF MS). ${ }^{79-80}$ In this technique the sample is co-crystalized with a matrix element ${ }^{\mathrm{a}}$ and evaporated in a high-vacuum chamber using a laser. The sample molecules become positively charged due to proton transfer from the acidic matrix species and can then be accelerated in an electric field. As mainly monocharged species are formed with a low degree of fragmentation their size can be determined based on their flight time to reach the detector.

\footnotetext{
${ }^{\text {a }}$ Such as $\alpha$-cyano-4-hyroxycinnamic acid 


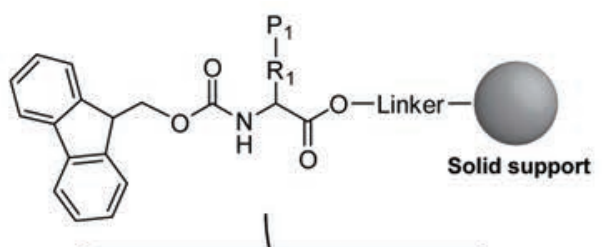

\section{First amino acid pre-attached}

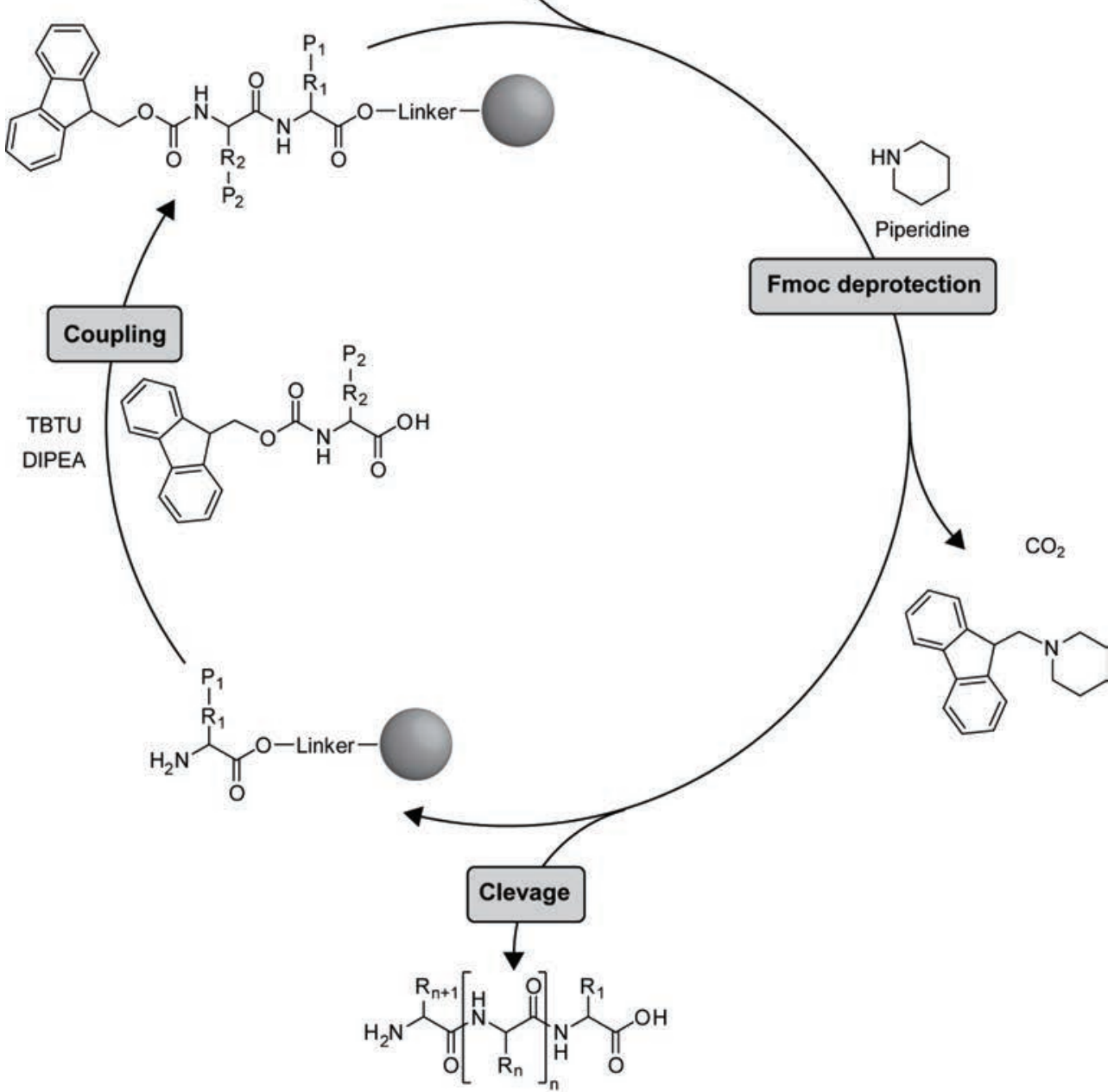

Figure 4.4 Schematic illustration of SPPS. Top: The first amino acid is attached to the solid support via a linker. Right: Fmoc deprotection makes the $\alpha$-amino group accessible for a further coupling. Left: Coupling step elongates the peptide. Bottom: Cleavage from the solid and side chain deprotection gives the final peptide. $R_{x}$ : Amino acid side chain, $P_{X}$ : Amino acid side chain protection group. 


\subsection{Peptide functionalization}

Polypeptides synthesized via SPPS can as previously mentioned be both cyclic and branched, ${ }^{74}$ but also functionalized with carbohydrates, ${ }^{74}$ fluorescent probes or recognition elements for a specific target. ${ }^{71}$ This is commonly achieved by utilizing an orthogonal protection strategy. An amino acid that can selectively be deprotected without affecting other protection groups present in the polypeptide is referred to as an orthogonally protected amino acid. This strategy was employed for the post-synthetically modification of the polypeptide KE2C, allowing for the selective incorporation of a $\mathrm{NHS}^{\mathrm{a}}$ activated benzenesulphonamide derivative at Lys 34. The Lys residue was protected with an Alloc ${ }^{\mathrm{b}}$ protection group which could be orthogonally deprotected by a treatment with $\mathrm{Pd}\left(\mathrm{PPh}_{3}\right)_{4}{ }^{\mathrm{c}}$. This polypeptide, KE2CC6, was used as a synthetic receptor for HCA II in paper I (Figure 4.3).

\subsubsection{Click chemistry}

An alternative to the use of orthogonal protection groups is to use the N-terminal amine after the final Fmoc deprotection step for functionalization of polypeptides. This strategy was used to realize a synthetic receptor, similar to KE2C-C6 but with the possibility to introduce the recognition element after peptide immobilization on gold nanoparticles, with the intention to create a highly versatile and generic sensor platform. This approach relied on the copper (I) catalyzed reaction between azide- and an alkyne moiety termed Huisgen's 1,3-dipolar cycloaddition for peptide functionalization (Figure 4.5a). This reaction was awarded "click chemistry" status by Sharpless et al. for its high selectivity, benign reaction conditions requirements, high thermodynamic driving force, otherwise inert chemical functionalities and its very high yield. ${ }^{81}$

In this approach an azide derivate was conjugated to the N-terminal of JR2EC (JR2EC-Az) before the final deprotection and cleavage step (Figure 4.5b). A wide range of different reducing agents for $\mathrm{Cu}$ (II) to $\mathrm{Cu}$ (I), catalysts, $\mathrm{pH}$ values, copper sources, buffers and other solvents were investigated to evaluate the best strategy for "clicking” an alkyne derivate to the polypeptide in solution. The best result where achieved at a surprisingly simple set of conditions where no added catalyst and only low concentrations of reduction agent ${ }^{\mathrm{d}}$ where required. By using $\mathrm{HEPES}^{\mathrm{e}}$ buffer, which can reduce the copper source $\mathrm{Cu}$ (II)SO $\mathrm{SO}_{4}$ to $\mathrm{Cu}$ (I) but do so only in the presence of suitable ligands, ${ }^{82}$ which presumably azide- and alkyne

\footnotetext{
${ }^{a} \mathrm{~N}$-hydroxysuccinimide

${ }^{\mathrm{b}}$ Allyloxycarbonyl

c Tetrakis(triphenylphosphine)palladium(0)

${ }^{\mathrm{d}}$ Ascorbic acid

${ }^{\text {e }} N$-(2-hydroxyethyl)-piperazine- $N$-ethanesulfonic acid 
moieties are as they coordinates $\mathrm{Cu}$ (I) during the cycloaddition. Accordingly a very fast and efficient coupling was achieved.

Three different alkyne containing sensing elements where conjugated to JR2EC-Az while in solution; a biotin derivate which interacts strongly with streptavidin (Figure 4.5c), a shorter version of the peptide fragment excised from the tobacco mosaic virus coat protein (TMVP) that was utilized in paper I which is recognized by the antibody fragment Fab57P (Figure 4.5d), and a benzenesulphonamide containing compound similar to the one present in KE2CC6 for the recognition of HCA II (Figure 4.5e). The MALDI-TOF spectra presented beneath each alkyne derivate in Figure 4.5c-e show the progress of the reaction after 30 minutes at room temperature with a stoichiometric ratio of JR2EC-Az:alkyne derivate of 1:2. This click chemistry approach for attaching recognition elements to JR2EC-Az while tethered to gold nanoparticles was, however, never realized as the alkyne containing derivatives were found to readily adsorb unspecifically to the particles spoiling their functionality.

a)

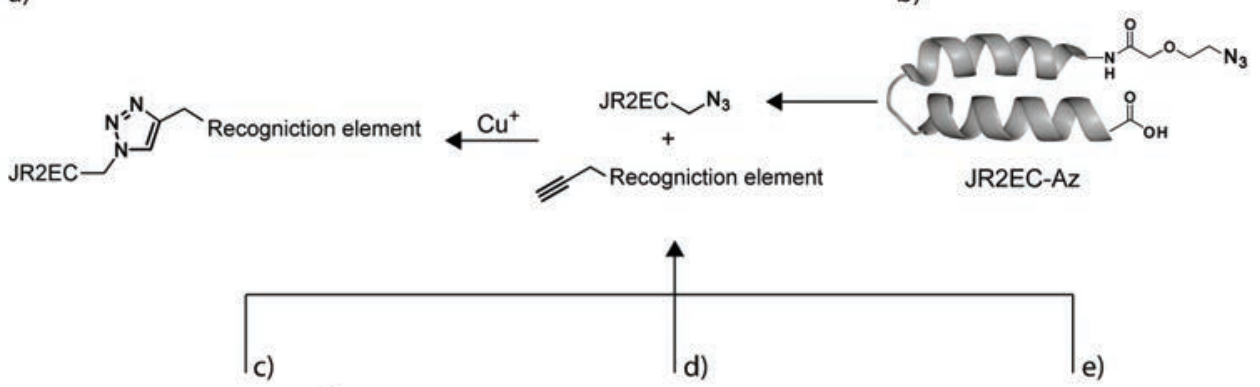

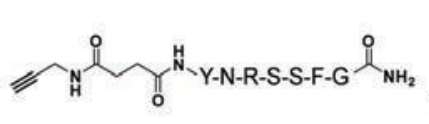<smiles>C#CCNC(=O)CCCCCNC(=O)c1ccc(S(N)(=O)=O)cc1</smiles>
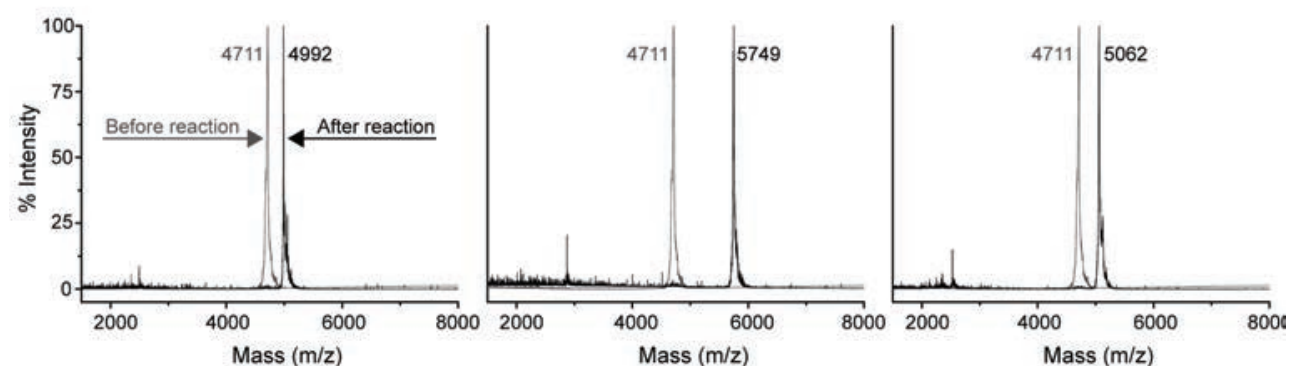

Figure 4.5 a) Huisgen's 1,3-dipolar cycloaddition between an azide and an alkyne moiety catalyzed by Cu (I). b) The N-terminal of JR2EC was functionalized through an amide coupling with an azide containing carboxylic acid compound. c) Biotin- d) TMVP- e) benzenesulphonamide derivatives containing alkyne functionalities with their corresponding MALDI-MS spectrum below for the reaction with JR2EC-Az. 


\section{CHAPTER 5}

\section{Metal Cations and Biomolecules}

Metal cations in biological systems are of profound importance as they can add key features to bioorganic molecules that they alone cannot accommodate. The main factor that determines their various functional roles is the strength of the interaction between the cations and the biomolecules they ligates. ${ }^{83} \mathrm{Na}^{+}$and $\mathrm{K}^{+}$generally interact weakly with organic ligands and are hence ideally suited for generating ionic gradients and maintaining osmotic balance. $\mathrm{Na}^{+}$ and $\mathrm{K}^{+}$are hence extensively used for this purpose for the generation of membrane potentials and for the propagation of nerve signals. The cations; $\mathrm{Mg}^{2+}, \mathrm{Zn}^{2+}$ and $\mathrm{Ca}^{2+}$ frequently interacts with biomolecules as they form moderately stable interactions and are commonly used to stabilize the folded structures of proteins. $\mathrm{Ca}^{2+}$, also serves as a secondary messenger in cellular signaling. ${ }^{83}$ The metal ions of copper and iron forms strong interactions with biomolecules and are extensively found in proteins and protein complexes involved in oxygen transports. They are also involved in numerous redox reactions as the catalytic cation in metalloproteins. ${ }^{83}$

\subsection{Metalloproteins}

Metal cations are an integrated cofactor in more than forty percent of all known proteins acting as a compliment to the natural occurring amino acids. ${ }^{84}$ The role of the metal ion differs from protein to protein and type of cation, ranging from stabilization of the native state to participating in enzyme catalysis. Alkaline metal ions such as $\mathrm{Na}^{+}$and $\mathrm{K}^{+}$often play a vital role in signaling transduction by interacting with a protein receptor invoking a response. ${ }^{85}$ Transition metals with a interchangeable valance state such as $\mathrm{Fe}, \mathrm{Mn}$ and $\mathrm{Cu}$ often facilitates electron transfer in redox reactions while $\mathrm{Ca}^{2+}, \mathrm{Mg}^{2+}$ and $\mathrm{Zn}^{2+}$ participate both in structural stabilization of proteins and the catalytic activity of non-redox enzymes. ${ }^{84} \mathrm{Zn}^{2+}$ alone is present in more than a thousand eukaryotic transcriptions factors as the DNA binding zinc finger motif. ${ }^{86}$

The metal ion binding site of metalloproteins are characterized by a shell of hydrophilic residues situated inside a grove or cavity within the protein, usually expelling the solvent at a successful ligation of the metal ion. The inner hydrophilic shell that ligates the cation is often 
further embedded in an outer hydrophobic shell creating a binding site with a high hydrophobic contrast. ${ }^{87}$ Most metalloprotein has a mononuclear binding site and selectively ligates one metal cofactor to attain its native fold or catalytic activity. Human carbonic anhydrase II (HCA II) is an example of a mononuclear metalloprotein involved in the respiratory process binding a single $\mathrm{Zn}^{2+}$ atom that is essential for its reversible hydration of $\mathrm{CO}_{2}$. HCA II was used as a model protein in paper I (Figure 5.1a). The ligated $\mathrm{Zn}^{2+}$ acts as a Lewis acid and lowers the $\mathrm{pK}_{\mathrm{a}}$ of a ligated water molecule making it prone for a nucleophilic attack on a $\mathrm{CO}_{2}$ molecule. ${ }^{88}$ Metalloproteins are not restricted to a single mononuclear binding site and can contain several metal ions capable of providing different functionalities. The matrix metalloprotease matrilysin (MMP-7) utilized in paper II contains four binding sites in each domain. Two of them are selective for $\mathrm{Ca}^{2+}$ and have a purely structural role and two are selective for $\mathrm{Zn}^{2+}$. One of the $\mathrm{Zn}^{2+}$ biding sites is catalytically active and one is of a structural character (Figure 5.1b). ${ }^{89}$ MMP-7 plays a critical role in the physiological and pathological degradation of extracellular matrix and share the same metal ion binding pattern as HCA II with three His residues and a water molecule coordinating the $\mathrm{Zn}^{2+}$ in the active site. Metalloproteins are also not restricted to a single metal ion in the catalytically active site and may comprise of a multitude of metal cofactors working synchronously during the catalytic process. The catalytic site of alkaline phosphatase (ALP) consists of a catalytic metal triad, with two $\mathrm{Zn}^{2+}$ and an $\mathrm{Mg}^{2+}$ with different chemical surroundings working sequentially in the hydrolysis of phosphate monoesters (Figure 5.1c). This process is explored in paper IV..$^{90}$

a)

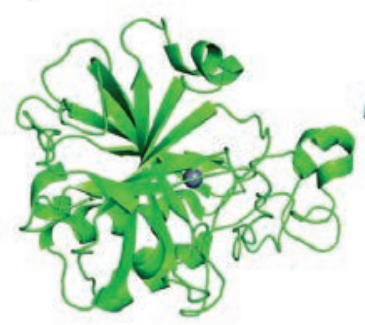

b)

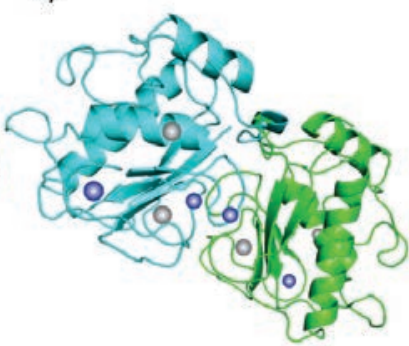

c)

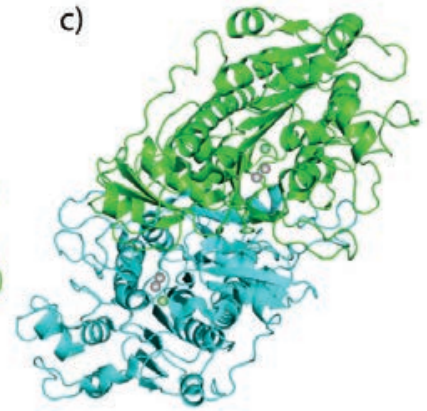

Figure 5.1 Crystal structure of a) carbonic anhydrase II (PDB entry $1 \mathrm{CAC}^{91}$ ) b) matrilysin (PDB entry $1 \mathrm{MMP}^{89}$ ) and c) alkaline phosphatase (PDB entry $1 \mathrm{ED}^{90}$ ) with cofactors $\mathrm{Zn}^{2+}$ (grey), $\mathrm{Ca}^{2+}$ (blue) and $\mathrm{Mg}^{2+}$ (green). All metal ions have been enlarged for clarity. 


\subsection{Attributes of zinc(II)}

$\mathrm{Zn}^{2+}$ is a very common element in metalloproteins, as illustrated above, both as a stabilizer of structural motifs and for providing catalytic related functions. ${ }^{92}$ The reason for the prevalence of $\mathrm{Zn}^{2+}$ is because it has a completely saturated $d$-shell giving it several beneficial properties in terms of coordination geometry and range of possible ligands. This electron configuration implies that $\mathrm{Zn}^{2+}$ has no ligand field stabilization energy in any coordination mode. Meaning that it has no preferred ligand arrangement over others, which is a common situation for other metal ions with only a partially filled $d$-shell. ${ }^{86} \mathrm{Zn}^{2+}$ also lacks any redox activity under physiological conditions and readily undergoes fast ligand substitutions. It is also considered as a borderline acid in terms of hard-soft acid base theory allowing for a broad spectrum of possible ligands. Several amino acid side chain functionalities can hence function as potential ligands, ranging from the soft thiolate group of cysteine to the hard carboxylates groups of aspartate and glutamate, as well as the imidazole group of histidine. ${ }^{86,93}$ The interaction with hard ligands even extends to the interaction with carbonyl functionalities in side chains and in the polypeptide main chain as well as in substrates and inhibitors, a property otherwise not commonly encountered in the binding site of other metal ions. ${ }^{92} \mathrm{Zn}^{2+}$ also interacts with both water and the hydroxyl ion, which is a key feature in many of its catalytic roles in enzymes.

\subsection{Zinc(II) - biomolecule interactions}

The interactions between cations and smaller biomolecules compared to the metalloproteins are also essential for various cellular functions but can also have a negative impact on the bioavailability of cations such as $\mathrm{Zn}^{2+}$. For instance, presence of high concentrations of strongly chelating species such as phytic- and folic acid (vitamin $\mathrm{B}_{9}$ ) in diet can severely affect the amount of metal ions available (Figure 5.2a), reducing the nutrition value of food and feedstuff. Zinc deficiency caused by presence of high concentrations of phytic acid in food can cause a range of pathological conditions in humans, especially in small children and adults already suffering from malnutrition. ${ }^{94-97}$ Both these chelants are found in high concentrations in plants and plant seeds, such as grain, ${ }^{98}$ and are commonly associated with $\mathrm{Zn}^{2+}$-deficiency in developing countries. Phytic acid in particular can also form ternary complexes, ${ }^{93,} 99$ sharing the central metal ion with another ligand to create a full coordination sphere. This property in combination with is high concentrations in certain diets can also limit the available protein-content as proteins can be enveloped by a network of polynuclear complexes of phytic acid and cations. ${ }^{99}$ 
a)<smiles>O=POC1C(OP)C(OPO)C(OPO)C(OPO)C1OPO</smiles>

Phytic acid<smiles>Nc1nc(O)c2nc(CNc3ccc(C(=O)NC(CCC(=O)O)C(=O)O)cc3)cnc2n1</smiles>

Folic acid<smiles>O=C(O)C(=O)O</smiles><smiles>O=C(O)CN(CCN(CC(=O)O)CC(=O)O)CC(=O)O</smiles>

EDTA

b)
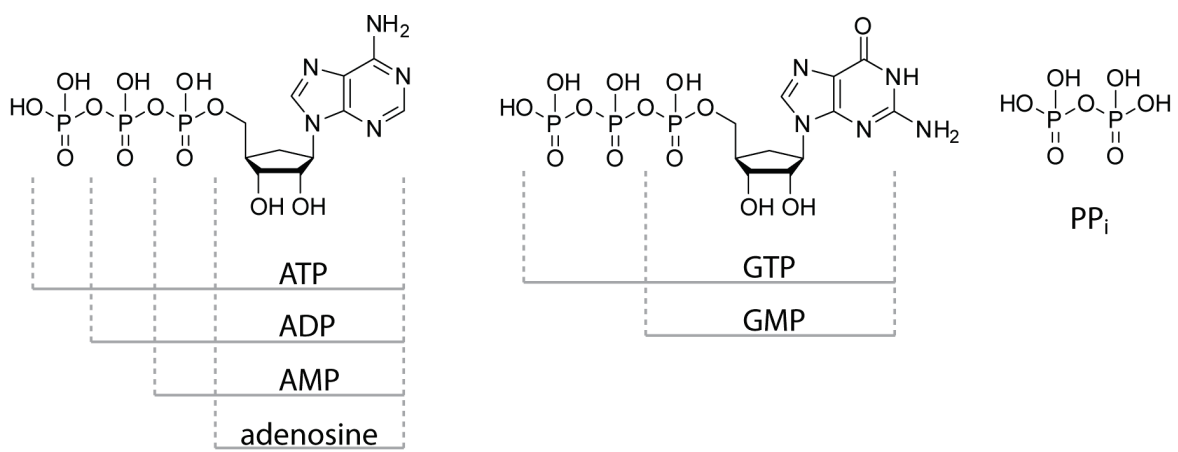

Figure 5.2 Chemical structures of common low molecular weight biomolecular chelants in their protonated forms.

The effects on $\mathrm{Zn}^{2+}$ induced particle aggregation by phytic- and folic acid, as well as the biologically relevant chelant oxalic acid, was investigated in paper III. In this paper the commonly used chelating agent EDTA ${ }^{\mathrm{a}}$ was also included as a reference compound (Figure 5.2a). The main effect on colloidal stability was caused by the ability of some of these compounds to form ternary complexes with the immobilized polypeptide. This property enabled phytic acid to be 300 times more efficient at modulating colloidal stability than the much stronger chelant EDTA.

Metal cation also interacts with NTPs ${ }^{b}$ such as ATP $^{c}$ and GTP $^{d}$ (Figure 5.2b). In fact, virtually all reactions involving NTPs also involves metal cations directly coordinated to the nucleotide or as integrated cofactors in the enzymes that hydrolyze them. ${ }^{100}$ The high-energy phosphate ester bond in NTPs makes them the primary energy carriers in the cell and they are thus substrates in a countless number of metabolic reactions. Their hydrolyzed derivatives

\footnotetext{
${ }^{\text {a }}$ Ethylenediaminetetraacetic acid

${ }^{\text {b }}$ Nucleoside 5'-triphosphate

c Adenosine 5'-triphosphate

${ }^{\mathrm{d}}$ Guanosine 5'-triphosphate
} 
also coordinate cations but to a smaller extent as the number of inorganic phosphates groups decrease. The logarithmic stability constants (log K) for these complexes with the common enzymatic cofactors $\mathrm{Zn}^{2+}, \mathrm{Mg}^{2+}$ and $\mathrm{Ca}^{2+}$ are shown in table 5.1. The high energy phosphate ester bond is also present in pyrophosphate $\left(\mathrm{PP}_{\mathrm{i}}\right)$ which in higher organisms is generated by NTP hydrolysis. $\mathrm{PP}_{\mathrm{i}}$ can in certain lower organism act as a substitute for NTPs under anaerobe condition, whereas in higher organisms it has a critical role in regulating extracellular calcification. ${ }^{101}$

All mono-, di- and tri 5'-nucleotides forms monomeric (1:1) complexes with divalent cations (M) while $\mathrm{PP}_{\mathrm{i}}$ mainly forms $\left[\mathrm{M}\left(\mathrm{PP}_{\mathrm{i}}\right)_{2}\right]$ complexes. ${ }^{102-103}$ They all have in common that their hydrolysis produces inorganic phosphate $\left(\mathrm{P}_{\mathrm{i}}\right)$, which forms insoluble complexes in the form of $\left[\mathrm{M}_{3}\left(\mathrm{PO}_{4}\right)_{2}\right] .{ }^{104}$ The logarithmic solubility constant (log $\mathrm{K}_{\mathrm{sp}}$ ) for these complexes can be found in table 5.1. $\mathrm{P}_{\mathrm{i}}$ generation as a consequence of NTP or $\mathrm{PP}_{\mathrm{i}}$ hydrolysis can markedly reduce the available cation concentration in a solution, due to the insolubility and stoichiometric ratio of the complexes formed. Enzymes that hydrolyze NTPs or $\mathrm{PP}_{\mathrm{i}}$ can thus be detected based on the reduction of the soluble metal ion content in a sample. This concept was developed for monitoring of phosphatase activity using the chelants in figure 5.2b as substrates in paper IV, where the concomitant effect on the $\mathrm{Zn}^{2+}$ concentration in the sample was exploited to produce a colorimetric response using the $\mathrm{Zn}^{2+}$-responsive polypeptide functionalized gold nanoparticles.

Table 5.1 Logarithmic stability and solubility constants.

\begin{tabular}{|c|c|c|c|c|c|c|c|}
\hline & & Log K & & & $\log K_{s p}$ & & Reference \\
\hline & $\mathrm{Zn}^{2+}$ & $\mathrm{Mg}^{2+}$ & $\mathrm{Ca}^{2+}$ & $\mathrm{Zn}^{2+}$ & $\mathrm{Mg}^{2+}$ & $\mathrm{Ca}^{2+}$ & \\
\hline ATP & 5.16 & 4.29 & 3.91 & - & - & - & 102 \\
\hline ADP & 4.28 & 3.36 & 2.95 & - & - & - & 105 \\
\hline AMP & 2.38 & 1.62 & 1.48 & - & - & - & 105 \\
\hline Adenosine & 0.24 & - & - & - & - & - & 105 \\
\hline GTP & 5.52 & 4.31 & 3.96 & - & - & - & 102 \\
\hline GMP & 2.65 & 1.73 & 1.54 & - & - & - & 106 \\
\hline$P_{i}$ & - & - & - & -31.49 & -25 & -32.68 & 104 \\
\hline$P P_{i}$ & 11.0 & - & - & - & - & - & 103 \\
\hline
\end{tabular}




\section{CHAPTER 6}

Colloidal Gold

The history of gold nanoparticles dates back to the $5^{\text {th }}$ or $4^{\text {th }}$ century BC in Egypt and China, where it was used for staining of glass and ceramics giving them an extraordinary colorful appearance. ${ }^{107}$ During the middle-ages alchemist where able to prepare "soluble gold" or "colloidal gold" and called it "an elixir of life". 108 The effects where perhaps a bit exaggerated as none of the users are alive today. It was through the discovery of "aqua regia", Latin for "royal water", ${ }^{a}$ that bulk gold could be reduced to $\mathrm{HAuCl}_{4}{ }^{\mathrm{b}}$, which could be dissolved in an aqueous solution. ${ }^{108}$ Soluble gold was used for the treatment of all sorts of illnesses, from melancholia to hearth problems. Originally these solutions seldom contained colloidal gold but rather the salt-form if they contained any gold at all. As time progressed, more standardized methods for the preparation colloidal gold were described. However, the negative effects of these treatments also became apparent and the use of colloidal gold in medicine became less popular. The so called Lange colloidal gold test was though still in use until the mid-20 $0^{\text {th }}$ century for diagnosis of syphilis. ${ }^{109}$

In the middle of the $19^{\text {th }}$ century Michael Faraday formulated the foundation of the modern colloidal science by using a more scientific approach. He developed a new synthesis method for obtaining stable suspensions of colloidal gold and further used it to form thin films. ${ }^{110} \mathrm{He}$ also investigated the optical properties of colloidal gold and observed that if he applied mechanical pressure to the films they underwent a reversible color change. It was however Graham that a few years later coined the term "colloid”. 111

During the latter half of $20^{\text {th }}$ century, intense investigations lead to the development of new synthesis methods for obtaining gold nanoparticles and more detailed studies on their physicochemical properties such as shape and size dependent optical, magnetic and electronic properties were performed. ${ }^{112-116}$ A more in-depth knowledge of the nature of gold nanoparticles has led to their reintroduction into medicine as diagnostic tools, ${ }^{117-120}$ and therapeutic agents, ${ }^{119-121}$ but also into other fields of science such as chemistry, electronics and material science.

\footnotetext{
${ }^{\text {a }}$ A mixture of nitric acid and hydrochloric acid, preferably in the ratio of 1:3.

${ }^{\mathrm{b}}$ Hydrogen tetrachloroaurate
} 


\subsection{Gold nanoparticle synthesis}

Just like the procedures used by the middle-age alchemists, modern gold particle synthesis is often based on the gold(III) derivate $\mathrm{HAuCl}_{4} \cdot{ }^{107-108}$ When dissolved in water it can be reduced to yield nearly spherical particles. This geometry is preferred as it has the smallest surface area and hence the lowest energy. ${ }^{122}$ The mono-dispersity and size of the particles are two important parameters that need to be controlled in order to give a useful material.
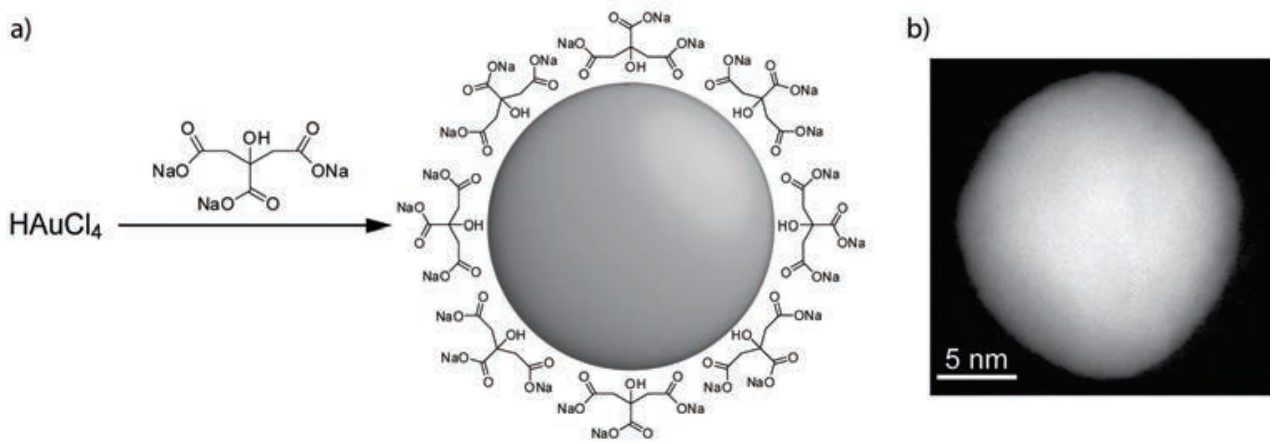

Figure 6.1 a) Schematic presentation of gold nanoparticles prepared by the reduction of $\mathrm{HAuCl}_{4}$ by citrate. b) Electron micrograph of a $20 \mathrm{~nm}$ gold nanoparticle obtained using high-angle annular dark-field (HAADF) imaging scanning transmission electron microscopy (STEM).

One of the most common methods for the preparation of colloidal gold is the reduction of $\mathrm{HAuCl}_{4}$ by citrate in a water solution (Figure 6.1). This method was established by Turkevitch and later refined by Frens and yields particles of a pre-chosen size between 10 $150 \mathrm{~nm} .{ }^{112-113}$ The size of the particles can be controlled by varying the $\mathrm{HAuCl}_{4}$ to citrate ratio. Citrate acts both as a reduction agent and as an anionic stabilizer by forming a multilayer around the final particle, giving it an overall negative charge. This method has two distinct advantages, where one is that the stabilizing citrate can be readily replaced allowing for easy functionalization of the particle and the other one is that biomolecules can be used for functionalization since the synthesis is performed in an aqueous medium. ${ }^{26,123}$ Unmodified particles prepared by this route are sensitive to changes in ionic strength and $\mathrm{pH}$ of the surrounding media but also towards organic contaminants which can cause irreversible aggregation. ${ }^{124}$ All gold nanoparticles used in this thesis are produced via citrate reduction of $\mathrm{HAuCl}_{4}$, although using different protocols. In paper I a procedure first described by Storhoff was used which produced $13 \mathrm{~nm}$ particles, ${ }^{125}$ in paper II the protocol described by Frens was used giving particles of $17 \mathrm{~nm}$ whereas in paper III-IV commercially available citrate stabilized nanoparticles particles were used which had a size of $20 \mathrm{~nm}$. 


\subsection{Optical properties of gold nanoparticles}

Gold nanoparticles exhibit several interesting optical properties that make them useful in numerous fields of science and they have been extensively used for sensing applications. Their interaction with visible light is a source to a phenomenon called local surface plasmon resonance (LSPR) which gives a suspension of spherical gold nanoparticles its characteristic deep wine-red color. The wavelength of the incident light is significantly larger than the size of the particles, which thus experience the electromagnetic field as homogeneous. This causes the electrons in the conduction band at the nanoparticle surface to collectively shift from their equatorial position. A restoring force consisting of the subsequent columbic attraction in combination with the oscillating electromagnetic field of the incident light, which when in resonance, causes the electrons to collectively oscillate with respect to the metal core (Figure $6.2)^{2,122,126-128}$

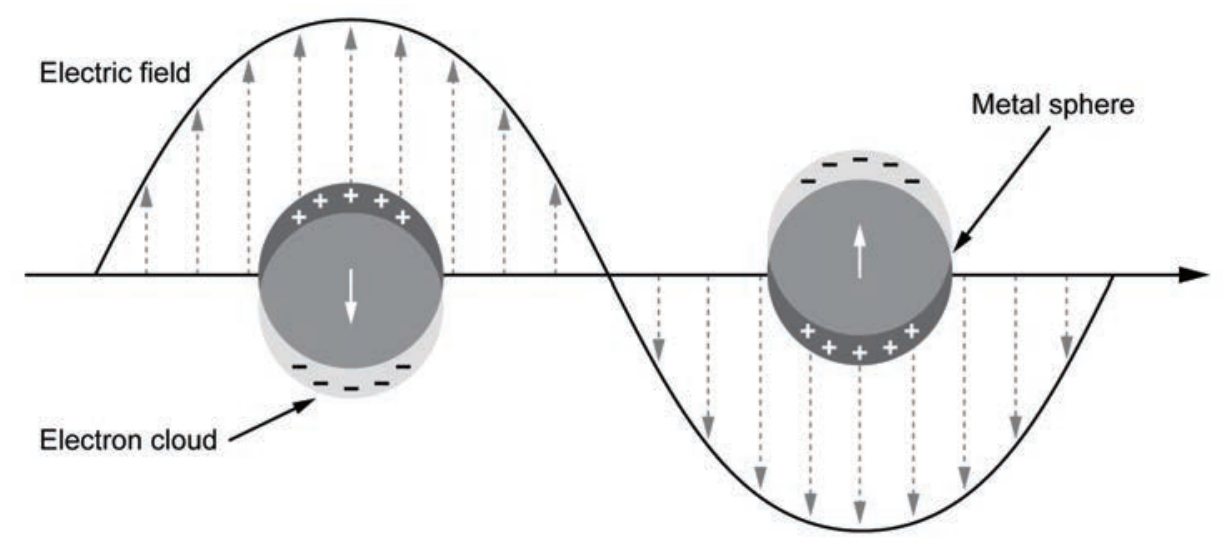

Figure 6.2 Schematic illustration of a metal sphere interacting with the electric field of light, inducing a local surface plasmon resonance. Redrawn from ${ }^{2}$.

The energy required to move the electrons from their equilibrium positions result in light being absorbed. For a $20 \mathrm{~nm}$ gold nanoparticle this absorption occurs around $525 \mathrm{~nm}$, which is in the green range of the visible spectrum (Figure 6.3). Red light is absorbed and scattered to a significantly lower extent, why the suspensions appear red. Several factors influence the frequency at which the electron oscillates such as metal composition, size and shape of the nanoparticles but also the refractive index of the surrounding medium. Local refractive index changes, caused by for example adsorption of a biomolecule on the particle surface, can hence be identified as the resonance mode changes and consequently shifts the LSPR band. The magnitude of the shift varies with both the refractive index of the adsorbed layer and its thickness. This effect can be used in refractive index sensors but the size of the shifts is typically quite small for spherical gold nanoparticles although higher sensitivities can be 
obtained utilizing different shapes and noble metal compositions of the particles. ${ }^{129-131} \mathrm{~A}$ much larger shift is however observed when the interparticle distance is decreased and the electric field generated by the oscillating electrons starts to overlap. The resulting shift in the LSPR band is highly dependent on the size and density of the aggregates and can be dramatic. For $20 \mathrm{~nm}$ gold nanoparticles the position of the extinction peak $\left(\lambda_{\max }\right)$ can be red-shifted from $\sim 525 \mathrm{~nm}$ to $\sim 615 \mathrm{~nm}$ which corresponds to a color change of the suspension from red to blue/grey (Figure 6.3). These shifts occur gradually and can be roughly described by an exponential function of the interparticle distance, where denser aggregates with smaller interparticle distances results in larger shifts. ${ }^{132-134}$ This phenomenon is termed plasmon coupling and can be used for sensor applications if the change in colloid stability can be linked to the presence of the species intended for detection. Plasmon coupling is used in all four papers included in this thesis as a transducer mechanisms resulting in a tunable colorimetric response for the detection of various proteins, biomolecules and enzymatic reactions.
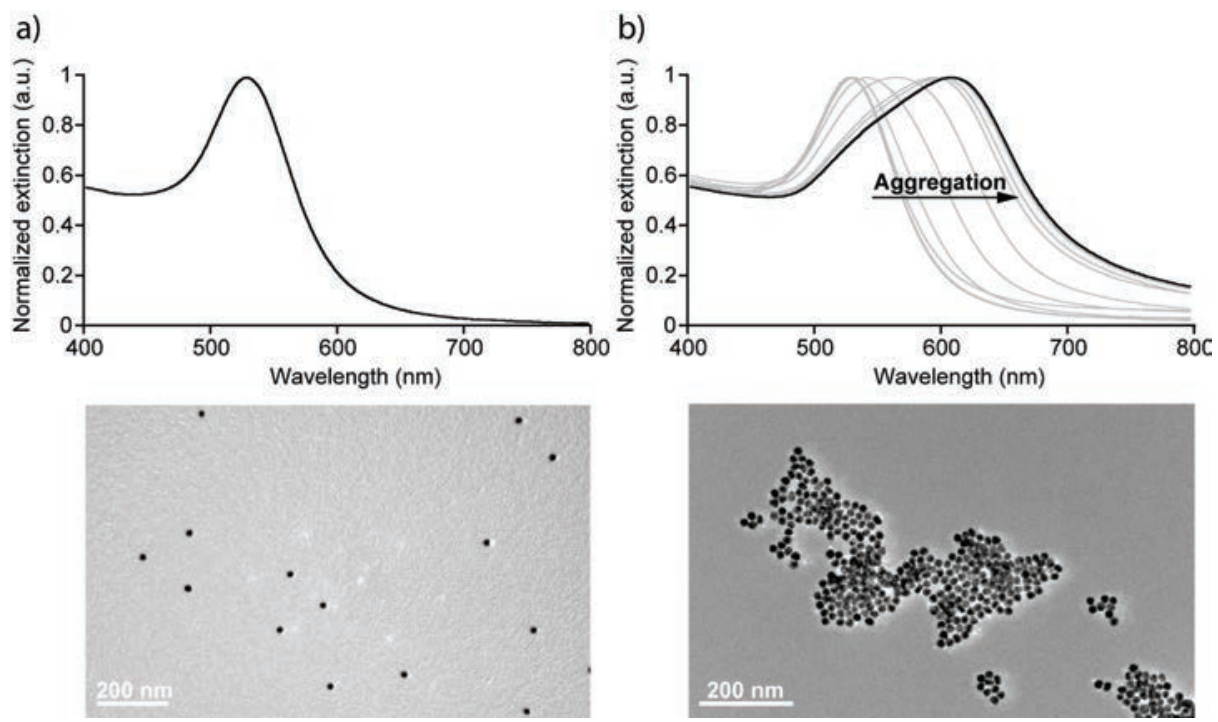

Figure 6.3 UV-visible spectra and corresponding electron micrographs of a) dispersed and b) aggregated gold nanoparticles. 


\subsection{Colloidal stability}

Solid nanoparticles dispersed in a liquid medium continuously undergo Brownian motion and frequently collide. It is the balance between the attractive and repulsive forces between the particles that determine if they separate again or aggregate. Colloidal suspensions that can resist aggregation and remain dispersed are said to be stable. A stable colloidal suspension is often preferred but it is however very useful to be able to control the stabilizing mechanisms in order to assemble the particles in a controllable fashion. This part of the thesis describes some of the most important forces that determine the stability of the colloid. The forces dealt with are divided into DLVO related forces which includes; van der Waals and electrostatic forces, and non-related DLVO forces which include steric and hydration forces.

\subsubsection{DLVO forces}

The classical work of Derjaguin and Landau in 1941 and of Verwey and Overbeek in 1948 formed the basis for the DLVO theory. ${ }^{135}$ It describes colloidal stability as the sum of the van der Waals interaction which is attractive in its origin and the electrostatic interaction which is repulsive. The electrostatic part of the DLVO theory arises as a consequence of accumulation of ions around the particle. Particles are usually charged either as a result of ionization of surface groups or by preferential adsorption of ions. In an electrolyte solution counter ions are attracted to the surface in order to balance the preexisting surface charge creating the Stern layer. The homogeneously charged Stern layer attracts a second layer of counter ions which are only loosely associated. This layer is the diffuse electric double layer and is the source of the repulsive force in the DLVO theory (Figure 6.4a). The magnitude of this force is highly dependent on the surface charge i.e. the ability to attract a diffuse electric double layer and the concentration of electrolytes in the solution. As the interparticle distance is decreased and the volumes occupied by the diffuse electric double layer starts to overlap the configurational entropy of the counter ions is decreased which leads to an osmotic repulsion. The attractive component, the van der Waals forces are always present and always attractive between two similar particles and will be predominate at very short distances. An idealized case is described in figure 6.4b where a highly charged particle in a diluted medium experiences an energy barrier that effectively prevents aggregation. A decreased surface potential or a higher electrolyte concentration will cause the sum of the forces to generate at secondary potential minima. If the energy barrier at contact remains too high to be exceeded the particle may reside in the local secondary minima or remain dispersed. At a concentration of electrolyte known as the critical coagulation concentration the interaction energy will be negative $(\mathrm{W}<$ 0 ) and the particles will aggregate and the colloidal suspension is referred to as unstable. ${ }^{135}$ 
a)

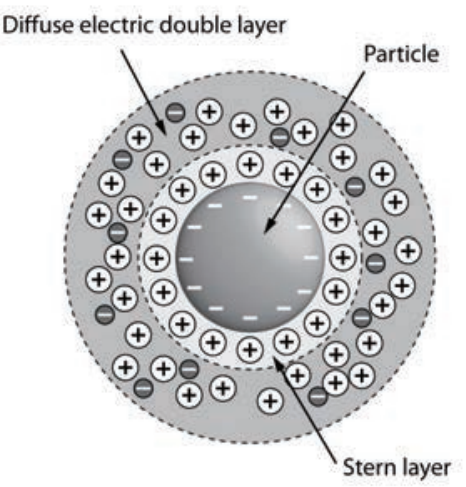

b)

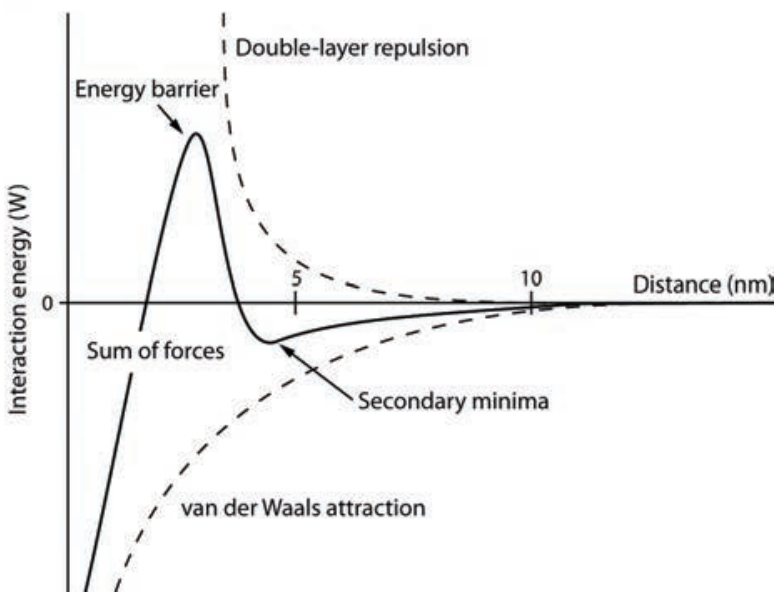

Figure 6.4 a) Schematic illustration of the electrostatic double-layer. b) Interaction energy (W) as a function of distance (D) according to DLVO theory. Figure 6.4b adopted form ${ }^{135}$.

\subsubsection{Non-DLVO forces}

The DLVO theory assumes that the interacting particles have well defined and sharp boundaries which rarely is the case as particles in more complex solutions readily absorbs macromolecules giving them a diffuse appearance with properties depending on the adsorbed species. Consequently, the macromolecules can have a profound influence on the overall colloidal stability and can contribute both positively and negatively to the stability depending on their properties. Compression of this layer of adsorbed molecules as a result of decreased interparticle separation will result in a repulsive force commonly referred to as steric repulsion. The magnitude of the repulsion depends on the surface coverage, density and size of the adsorbed layer. The steric repulsion occurs as a result of the loss of conformational freedom experienced by the compressed layer and is considered as an entropic force. ${ }^{135}$ The magnitude of this force also depends on how the adsorbents interact with each other and with the solvent. A favorable adsorbent-absorbent interaction increases the attractive force between particles whereas a strong adsorbent-solvent interaction increases the particle stability.

All surfaces that are submerged in an aqueous medium will impose an ordering of the water molecules at the interface. Depending on the water-surface interactions, displacement and reorganization of the water molecules as a consequence of reduced interparticle distance can exceed the DVLO forces at short distances. This repulsive force referred to as the hydration force can be monotonic as well as oscillatory in nature. ${ }^{136}$ 


\subsection{Gold nanoparticles stabilized by JR2EC}

It is the sum of the forces described above that defines the overall stability of a colloidal system. The magnitude of some of them can be tuned by changing physicochemical parameters such as $\mathrm{pH}$ or electrolyte concentration, which primarily will affect the electrostatic repulsion leaving other forces unchanged. In order to trigger aggregation of the particles the sum of the forces must be shifted from stabilizing to destabilizing and there are numerous methods to achieve this, using both specific and unspecific interactions. In this thesis the polypeptide JR2EC was immobilized on nanoparticle and was utilized for modulating the stability of the colloids. JR2EC provides several possibilities to tune the colloidal stability.

Gold nanoparticles modified with JR2EC are remarkably stable and can withstand conditions that unmodified particles would not, such as physiological salt concentrations, repeated centrifugations and many different buffers. The stability is a combination of both the steric stabilization by the $4.6 \mathrm{kDa}$ polypeptide and electrostatic stabilization as a consequences of its relatively high negative net charge $\mathrm{e}^{\mathrm{a}}$. This combination is often referred to as electrosteric stabilization and is a common method to stabilize colloidal systems. ${ }^{26,137}$ Immobilized JR2EC retains its responsiveness to $\mathrm{Zn}^{2+}$ and acidic $\mathrm{pH}$ values. Exposure to either results in a rapid and extensive particle aggregation. ${ }^{37}$ To investigate the influence of folding on the $\mathrm{Zn}^{2+}$

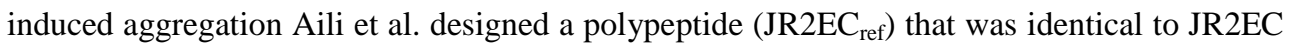
in all aspects except that all L-Ala residues were replaced by D-Ala. This peptide was not expected to fold under any circumstances and consequently showed no secondary structure in the presence of $\mathrm{Zn}^{2+}$ or at acidic $\mathrm{pH}$ values. Gold nanoparticles functionalized with this reference polypeptide did not respond to $\mathrm{Zn}^{2+}$ indicating that folding indeed was a requirement for the $\mathrm{Zn}^{2+}$ induced aggregation. ${ }^{37}$ It is however likely that it is a combination of effects that causes the aggregation in the presence of $\mathrm{Zn}^{2+}$ where electrostatic repulsion probably needs to be somewhat reduced for the particles to interact.

This colloidal system is highly sensitive to the $\mathrm{Zn}^{2+}$ concentration and aggregation occurs in a defined concentration interval. The $\mathrm{Zn}^{2+}$-concentration dependency is further described in chapter 7.2 and was used in paper I, III and IV. In paper II another approach was used which did not involve $\mathrm{Zn}^{2+}$ as the modulator of colloidal stability. Instead the electrosteric stabilization was reduced by enzymatic digestion of JR2EC.

\footnotetext{
${ }^{\text {a } J R 2 E C ~ h a s ~ a ~ n e t ~ c h a r g e ~ o f ~}-5$ at $\mathrm{pH} 7$.
} 


\section{CHAPTER 7}

\section{Polypeptide Functionalized Gold Nanoparticles}

Immobilizing polypeptides on nanoparticles to form stable and functional hybrid nanomaterials involves numerous different challenges that depend on the properties of the individual components. Characteristics of the polypeptide that contributes are mainly its net charge, amino acid composition, size and conformation. ${ }^{138}$ The compositional diversity of a polypeptide, taking into account the various properties of the different amino acids, makes it very complex to predict how the molecule will adsorb on a surface. Multiple interactions are often formed between the peptide and the surface which can have a significant influence on both the conformation and structural flexibility of the peptide backbone, which hence will influence its function and possibilities to interact with other biomolecules. ${ }^{47}$ A polypeptide with a defined secondary structure may lose structure as a consequence of its interaction with the interface, or if designed accordingly it may actually fold as a result of this interaction. ${ }^{62}$ The characteristics of the nanoparticles that influence the interaction are their composition, size, curvature, shape and crystallinity. ${ }^{47}$ The adsorption of molecules on solid substrates can be divided into physisorption and chemisorption. Physisorption leaves the chemical species of the adsorbate and the surface intact and is the result of van der Waals, electrostatic and hydrophobic forces. Chemisorption involves a chemical reaction between the adsorbate and the surface, generating a new chemical bond. ${ }^{139}$

In this thesis the conventional chemisorption strategy for the immobilization of organosulfur deviates onto gold surfaces have been extensively employed. The bond formed between a thiol or disulphide and a gold substrate can be described as a slightly polar covalent bond. ${ }^{140}$ Lateral diffusion and rearrangement of adsorbed sulfur derivates on a flat gold surface can lead to the formation of self-assembled monolayers (SAMs). Well organized SAMs can form as a result of stabilizing intermolecular interactions, such as van deer Waals forces, that in the case of alkane thiols can yield SAMs with almost crystalline structure. ${ }^{141}$ SAM formation on a spherical gold nanoparticle abide by the same principles, however, as the space occupied by the adsorbate changes from a cylindrical volume on a flat surface to a conical volume on a spherical surface lateral interactions are decreased. The available conical volume is related to the curvature of the particle and hence its size. The increased volume available allows for a 
more flexible conformation of the adsorbates and may also lead to an increased ratio of adsorbates per surface gold atom. ${ }^{142}$

Synthesis of gold nanoparticles via the reduction of $\mathrm{HAuCl}_{4}$ by citrate as described in chapter 6.1 produces citrate stabilized particles. In order to functionalize these nanoparticles the citrate layer must be removed, hence a ligand exchange reaction must take place. Consideration must be taken to the resulting loss of stability and a suitable replacement adsorbate must be used to avoid aggregation.

\subsection{Immobilization of JR2EC onto gold nanoparticles}

Immobilization of the polypeptide JR2EC onto gold nanoparticles was accomplished using the thiol group found in the cysteine residue located in the loop region of the polypeptide. Replacement of the stabilizing citrate molecules by JR2EC produced gold particles with impressively high colloidal stability. Functionalization was easily performed by incubating citrate stabilized gold particles with $100 \mu \mathrm{M}$ JR2EC in a citrate buffer for at least eight hours. Repeated centrifugations and buffer exchanges afforded a convenient way of removing excess non-immobilized polypeptides, which could be reduce to the low $\mathrm{pM}$ range without reducing the stability of the colloid. The high colloidal stability further enabled the use of a range of different buffers throughout the different papers. Additionally, the polypeptide functionalized particles proved surprisingly resistant to adsorption of various proteins such as IgG, HCA II, ALP, PPase and apyrase, however physiological concentrations of abundant proteins like HSA ( 1 mM) do cause unspecific adsorption.

Immobilization of KE2C and the synthetic receptor KE2C-C6 onto gold nanoparticles could be performed using the same conditions as described for JR2EC without any noticeable complications.

\subsection{Zinc(II) induced aggregation}

The immobilization of the polypeptide JR2EC on gold nanoparticles creates a highly flexible hybrid nanomaterial which can be assembled by three different strategies: (i) the addition of the disulfide linked JR2KC which can heterodimerize with the tethered JR2EC bridging adjacent particles, ${ }^{143}$ (ii) lowering the $\mathrm{pH}$ below 6 induces aggregation as consequence of a reduced electrostatic repulsion resulting in homodimerization of peptides tethered to particles in contact, ${ }^{36}$ and (iii) that relies on the $\mathrm{Zn}^{2+}$ mediated aggregation, for which the mechanism have previously described in chapter 6.4 and that has been extensively utilized in this thesis. 
Aggregation induced by $\mathrm{Zn}^{2+}$ occurs in a rather narrow concentration span and leads to an extensive redshift of the plasmon band from $\sim 527 \mathrm{~nm}$ to $\sim 610 \mathrm{~nm}$ for $20 \mathrm{~nm}$ particles (Figure 7.1a), resulting in a clearly visible color change which saturates within minutes. By plotting the difference in the LSPR peak position $\left(\lambda_{\max }\right)$ as a function $\mathrm{Zn}^{2+}$ concentration the concentration dependency for the aggregation is clearly illustrated in Figure 7.1b, with the most profound changes occurring in the interval of $1-1.5 \mathrm{mM}$. Addition of $\mathrm{Zn}^{2+}$ above $2 \mathrm{mM}$ does not cause further changes in the LSPR band as dense aggregates have already formed (Figure $7.1 \mathrm{~b}$ and c). The responsiveness of the particle system to small variations in the $\mathrm{Zn}^{2+}$ concentration within this interval can be used to study several mechanisms that affect the concentration, such as the presence of chelators or reactions where reactants and products coordinate $\mathrm{Zn}^{2+}$ to different extents. Aggregation induced by $\mathrm{Zn}^{2+}$ is also reversible and removal of the $\mathrm{Zn}^{2+}$ causes the particles to become redispersed once again. This is demonstrated in paper III where addition of chelating agents readily disrupts the formed aggregates by sequestering the $\mathrm{Zn}^{2+}$ to an extent corresponding to their affinity for $\mathrm{Zn}^{2+}$.

a)

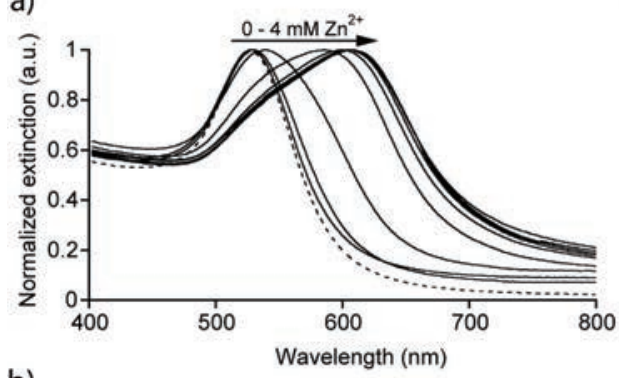

b)

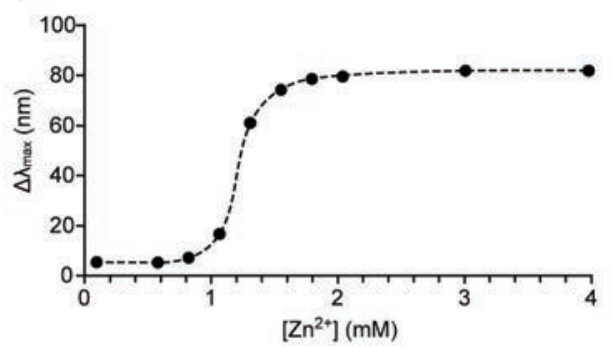

c)

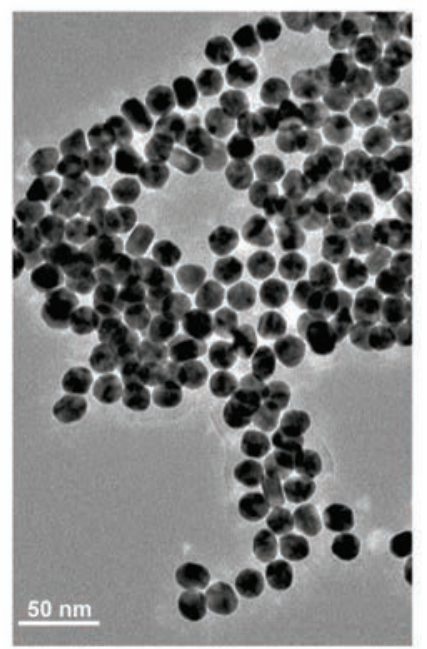

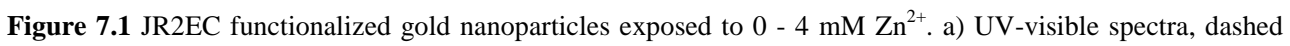
line indicates absence of $\mathrm{Zn}^{2+}$. b) $\Delta \lambda_{\max }$ as function of $\left[\mathrm{Zn}^{2+}\right]$. c) Electron micrograph of particles in the presence of $2 \mathrm{mM} \mathrm{Zn}^{2+}$. 


\section{CHAPTER 8}

\section{Gold Nanoparticles in Bioanalytical Applications}

Detection strategies that enable simple, rapid, cost efficient and sensitive monitoring of proteins and their interactions with biomolecules are of great importance in drug development and diagnostics. The detection of a disease marker in an early state of a pathological condition can facilitate treatment whereas the monitoring of an enzymatic reaction can be used for both screening of potential drug-candidates as well as allow for detection of the enzymes and their catalytic activities.

Gold nanoparticles have extensively been used for this purpose due to their chemical inertness, high-surface-to-volume ratio, accessible functionalization and optical properties. The first use of a gold nanoparticle based assay was for the diagnostics of syphilis in the early twentieth century where altered proteins in cerebrospinal fluids were detected. This test however proved unreliable and is not in use today. ${ }^{144}$ Gold nanoparticles were reintroduced several decades later as labels in electron microscopy where antibodies conjugated to the particle surface functioned as recognition elements. ${ }^{145-146}$ The last twenty years have witnessed an astonishing increase of gold nanoparticle based assays and sensors as new methods for their synthesis, functionalization with a large repertoire of recognition elements and innovative detection schemes have been developed. In general, a recognition element, which often is a biomolecule, binds the target analyte whereas the particles acts as transducer elements that report this event by giving rise to a detectable signal. In the case of gold nanoparticles the signal generation is often optical in origin due to the unique optical properties. Two distinctly different approaches can be used for biodetection were the first relies on the changes in refractive index that occur upon binding of an analyte to a recognition element attached to the particle. ${ }^{2,128}$ As the frequency at which local surface plasmon resonance conditions are fulfilled is dependent on the refractive index at close vicinity to the particle surface the binding event results in a small change that consequently shifts the LSPR peak position and intensity. The magnitude of the shift is typically small (a few nanometers) and is dependent on the noble metal composition, size and shape of the nanoparticles. The second approach can be described as distance dependent detection, where the optical signal arises due to overlap of the electric field generated by the oscillating electrons in LSPR. This effect called plasmon coupling starts to occur at an interparticle distance of less than one 
particle diameter and produces much larger shifts compared to those observed for refractive index sensors. ${ }^{147}$ The key concept in this type of assays is to induce aggregation either as a response to binding or by an external stimulus. If properly designed, simple and highly sensitive sensors can be produced where the readout can be performed by the naked eye. The first use of this distance dependent color changes was in sol particle immunoassays developed by Leuvering et al. several decades ago. ${ }^{148-149}$ The assays of that time combined particles with antibodies as the recognition elements where multivalent binding to an antigen produced cross-linked particles. Due to sheer size of the antibodies the interparticle distance could never be smaller than about $\sim 45 \mathrm{~nm}$ which consequently only produced minor color changes. Even though these types of assays where refined it was not until two decades ago that the true potential of distance dependent sensor could be realized into what is now commonly referred to as colorimetric sensors or assays.

\subsection{Colorimetric assays}

Mirkin et al. pioneered these types of assays by conjugating thiolated single stranded oligonucleotides to gold nanoparticles producing spherical nucleic acid (SNA) and could induce aggregation by the addition of complementary strands. ${ }^{26}$ The precision in the selfassembly mechanism governing the aggregation was such that even single base pair mismatches could be detected. ${ }^{125}$ This innovative approached lead to the development of many DNA based colorimetric assays, and later came to encompass detection strategies for other types of analytes such as amino acids, ${ }^{150}$ carbohydrates, ${ }^{151}$ enzymes, ${ }^{7,152}$ and also metal ions. ${ }^{6}$ Many of these detection schemes rely on the use of non-functionalized gold nanoparticles where the presence of a target analyte either induces or prevents aggregation. Scrimin et al. design a rapid method for the detection of protease activity where a peptide with a cysteine residue at each end was incubated with a sample; in the absence of the protease upon addition of non-functionalized particles the peptides cross-linked the particles whereas a digested peptide would not. ${ }^{5}$ This strategy enabled detection of the proteases thrombin and lethal factor Xa in the nanomolar range. Another approach was described by Li et al. where alkaline phosphatase activity could be detected based on that the substrate adenosine 5'triphosphate (ATP) and its hydrolyzed derivates could function as a stabilizing capping agent and prevent salt induced aggregation to different extents. ${ }^{153}$ These types of assays are very simple and rapidly performed but they are however sensitive to the presence of macromolecules in the sample that can adsorb to particle surface and are also prone to unspecific aggregation, both which can generate erroneous results. More robust assays can generally be developed using functionalized particles, as they can be design to withstand unspecific aggregation and unwanted adsorption of macromolecules. Even more versatile and 
in some cases generic assays can be developed if aggregation modulation can be successfully decoupled from the recognition event. Polypeptides has emerged as promising alternative to DNA in colorimetric assays as they have a more versatile chemical composition and because of that a wider scoop of functions and can be tailored both to function as recognition elements, ${ }^{71,154}$ and as assembly mediators. ${ }^{143,155-156}$

\subsection{Colorimetric protein sensing}

A common theme in colorimetric assays is that the recognition event is directly coupled to the stability of the particles and binding consequently triggers aggregation. As nanoparticle stability can be compromised by unspecific interactions or increased salt concentrations false positive results may arise. If the interaction with the analyte instead prevents aggregation this type of errors may be avoided. By immobilizing a receptor to the particles surface, binding of the target analyte may provide a steric obstruction that consequently will prevent aggregation. This approach relies on an alternative modulator for particle stability that is independent on recognition moiety and thus allows for the receptor-analyte pair to be exchanged creating a versatile sensor platform. This concept was developed in paper I where stability modulation was achieved by the $\mathrm{Zn}^{2+}$ responsiveness of JR2EC functionalized gold nanoparticles (Figure 8.1a). The validity of the approach was demonstrated using two different receptors, the polypeptide KE2C-C6 which is selective for HCA II and a polypeptide derived from tobacco mosaic virus coat protein (TMVP) which interacts with an antibody fragment (fab57P). Both analytes could be detected in the low nanomolar range as binding prevented the formation of dense aggregates induced by $\mathrm{Zn}^{2+}$ (Figure 8.1b). 
a) $\mathrm{Zn}^{2}+$ induced aggregation

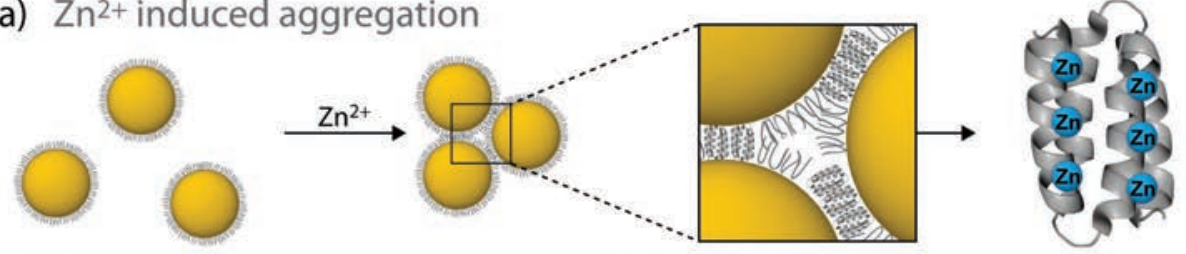

b) Paper I

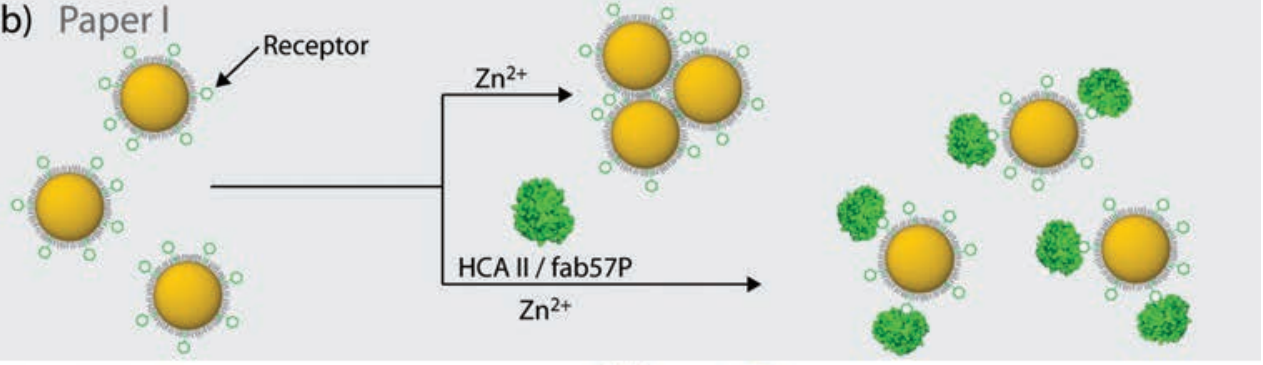

c) Paper II

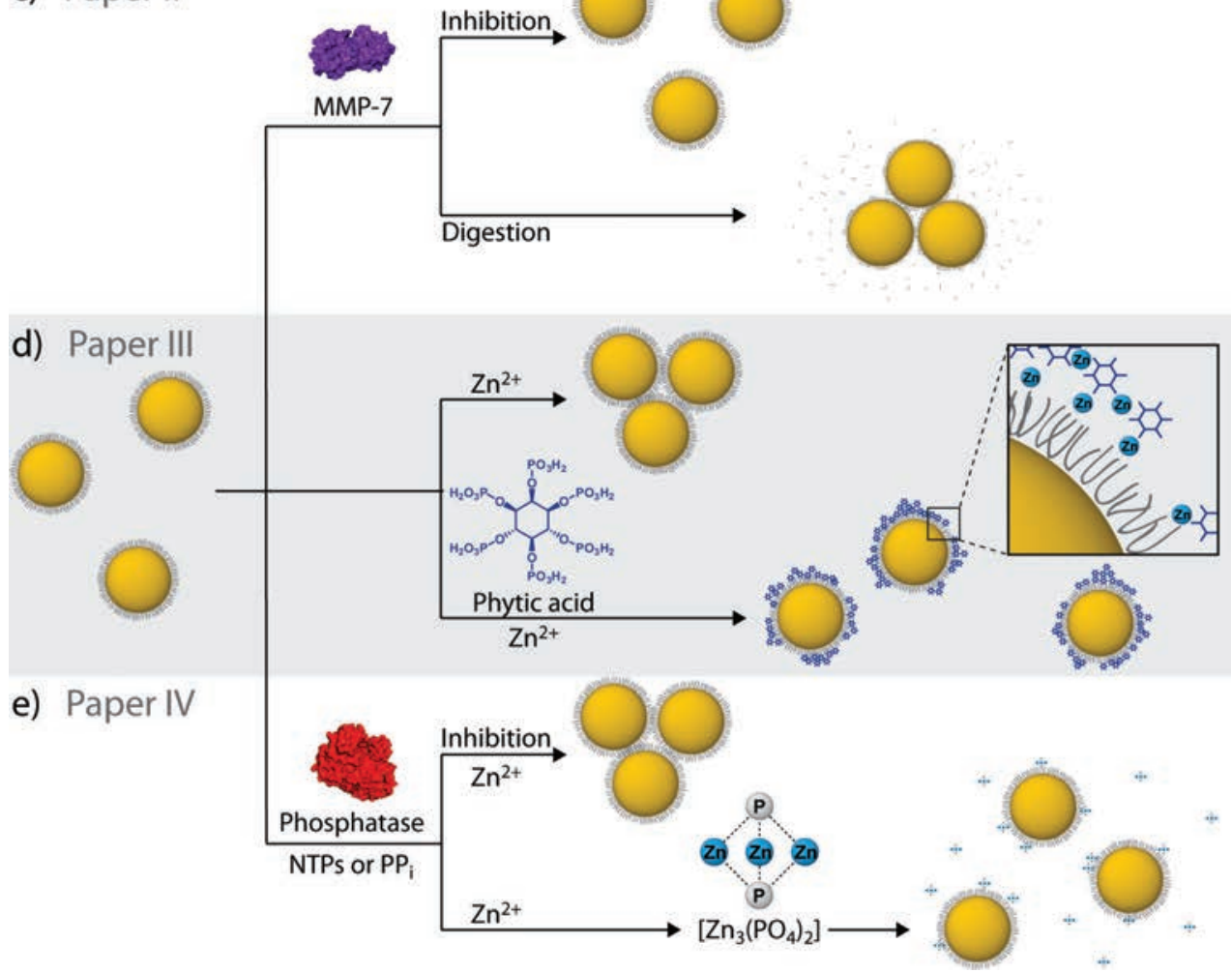

Figure 8.1 Schematic illustration of a) aggregation induced by $\mathrm{Zn}^{2+}$, strategies used for the detection of b) HCA II and fab57P, c) MMP-7, d) chelants such as phytic acid and e) phosphatases including ALP, apyrase and PPase utilizing their natural substrates. 


\subsection{Colorimetric protease sensing}

Sensors and assays that can monitor protease activity can be used both as diagnostic tools and for the evaluation of potential drugs candidates. Proteases are a large class of enzymes that have a central role in regulatory pathways by hydrolyzing other proteins which makes them useful as prognostic indicators for various pathological conditions, ${ }^{47}$ whereas drugs that target protease activity can be used to treat numerous diseases ranging from the common cold to cancers and ADIS. ${ }^{4}$ Proteases cleaves the amide bond in the polypeptide main chain and is often highly specific to what sequence is digested. In some cases an elevated concentration of a protease can be an indicator for a pathological condition such as in the case of the metalloproteinase matrilysin (MMP-7), where an increased concentration is an indicator for salivary gland cancer. ${ }^{157}$ In paper II a colorimetric assay for MMP-7 was developed that relies on the cleavage of the polypeptide JR2EC. MMP-7 digests JR2EC at two specific sites reducing the polypeptide to about a third of its original size and also decreases its net charge from -5 to -1 at neutral $\mathrm{pH}$. Gold nanoparticles functionalized with JR2EC accordingly aggregated in the presence of MMP-7 due to decreased electrosteric stabilization (Figure 8.1c). Inhibition of protease activity by depriving the metalloprotein of its metal cofactors with EDTA or the addition of the inhibitor II which binds to the catalytic zinc ion prevented digestion of JR2EC and the particles consequently remained dispersed. This assay proved very rapid as a colorimetric response was obtained within minutes with a detection limit of about $\sim 5 \mathrm{nM}$ which is well in line with the lowest values commonly displayed by salivary gland cancer patients.

\subsection{Colorimetric zinc-protein-chelant sensing}

Real-time monitoring and characterization of metal-protein-chelant interactions is challenging but important as these types of interactions are plentiful in biology and medicine. For example the coordination of $\mathrm{Zn}^{2+}$ by proteins and other organic molecules is essential for numerous biological processes such as in metabolism, enzyme catalysis and signal transduction. ${ }^{158}$ Resent findings also suggests that protein-zinc-protein interactions are an important factor in amyloid formation associated with Alzheimer's disease and that zinc-chelants can be used to modulate amyloid plaque formation. ${ }^{159-160}$ Furthermore the presence of small molecular chelators such as phytic acid in diet can have a profound effect on the bioavailability of $\mathrm{Zn}^{2+}$ and affect critical zinc-protein interactions. ${ }^{97}$ These types of interactions were probed in paper III utilizing the colorimetric response of $\mathrm{Zn}^{2+}$ induced aggregation of JR2EC functionalized gold nanoparticles. The effect of four different chelants on the $\mathrm{Zn}^{2+}$ induced aggregation was investigated and the aggregational state of the particles and hence the color of the suspension was found to correlate with the concentration, zinc binding affinity and coordination number 
of the chelants. The most important factor was concluded to be the coordination number where species like phytic- and folic-acid could form zinc-peptide-chelant complexes enveloping the particles in extensive networks that sterically prevented aggregation (Figure 8.1d).

\subsection{Colorimetric phosphatase sensing}

A general problem in the design of colorimetric assays is that the recognition event is often directly coupled to the stability modulation mechanism. New assay strategies are thus required for each new type of substrate or enzyme of interest. In paper IV a generic strategy was developed for the detection of phosphatase activities using their natural substrates where stability modulation was completely decoupled from the enzymatic activity. Phosphatases hydrolyze the high-energy phosphate ester bond in nucleoside 5 'triphosphatses (NTPs) and their derivates as well as pyrophosphate $\left(\mathrm{PP}_{\mathrm{i}}\right)$ and hence play a critical role in regulatory pathways. These phosphate containing compounds have in common that they all coordinated metal ions and virtually all reactions involving NTPs also involves metal ions directly coordinated to the nucleotides or as integrated cofactors in the hydrolytic enzymes. ${ }^{100}$ Even though the coordination capacity varies between the different phosphate containing compounds they all produce inorganic phosphate $\left(\mathrm{P}_{\mathrm{i}}\right)$ when hydrolyzed which have a higher coordination capacity towards $\mathrm{Zn}^{2+}$ than the starting materials. The $\left[\mathrm{Zn}_{3}\left(\mathrm{PO}_{4}\right)_{2}\right]$ complex formed is virtually insoluble and increasing the concentration of $\mathrm{P}_{\mathrm{i}}$ can effectively deprive a solution of its $\mathrm{Zn}^{2+}$-contents. The concentration of $\mathrm{Zn}^{2+}$ in a sample will thus be markedly reduced as a consequence of phosphatase activity towards NTPs and PP. As JR2EC functionalized gold nanoparticles are sensitive to the $\mathrm{Zn}^{2+}$ concentration and produce a proportional colorimetric response they can be used to monitor these types of reactions. This was demonstrated using three different phosphatases; alkaline phosphatase (ALP), apyrase and pyrophosphatase (PPase) catalyzing the hydrolysis of ATP/ADP/AMP, ATP/GTP and $\mathrm{PP}_{\mathrm{i}}$, respectively (Figure 8.1e). All phosphatases were studied as a function of concentration and could be detected in the low nanomolar range. The detection strategy was further used for both characterization of substrate specificity and for inhibitions studies giving dose responsive correlations that fitted well with previously reported values. 


\section{CHAPTER 9}

\section{Summary of Papers}

\section{PAPER I}

D. Aili, R. Selegård, L. Baltzer, K. Enander, B. Liedberg, ”Colorimetric Protein Sensing by Controlled Assembly of Gold Nanoparticles Functionalized with Synthetic Receptors”, Small 2009; 5, 2445-2452.

This paper describes a strategy for colorimetric sensing of proteins using polypeptide functionalized gold nanoparticles. Protein recognition was accomplished using a polypeptide sensor scaffold (KE2C-C6) that specifically bound the target protein analyte, human carbonic anhydrase II (HCA II). Co-immobilization of a secondary polypeptide (JR2EC) enabled $\mathrm{Zn}^{2+}$ induced aggregation as a consequence of folding and dimerization at the particle interface. The extent of the aggregation and the colorimetric shift was correlated to the concentration of HCA II and concentrations down to $15 \mathrm{nM}$ could be detected. Binding of HCA II to the synthetic receptor prevented aggregation whereas in its absence a major red shift of the plasmon band occurred. The versatility of the detection strategy was further demonstrated by implementing a second recognition system where an antibody fragment could recognize and bind a short peptide segment from the tobacco mosaic virus coat protein that was immobilized on the nanoparticles. 


\section{PAPER II}

P. Chen, R. Selegård, D. Aili, B. Liedberg, "Peptide Functionalized Gold Nanoparticles for Colorimetric Detection of Matrilysin (MMP-7) Activity” Nanoscale 2013; 5, 8973-8976.

Gold nanoparticles functionalized with the polypeptide JR2EC demonstrate excellent colloidal stability because the peptide provides both electrostatic and steric stabilization. The metalloprotease MMP-7, which is biomarker for salivary gland cancer, digests JR2EC at two specific sites, reducing the size and net charge of the immobilized polypeptide. The proteolytic digestion of JR2EC destabilized the particles, which consequently aggregated. The resulting colorimetric shift was proportional to the concentration and activity of MMP-7 and enabled detection down to $\sim 5 \mathrm{nM}$.

\section{PAPER III}

W. C. Mak, ${ }^{\dagger}$ R. Selegård, ${ }^{\dagger}$ M. Garbrecht, D. Aili, "Probing Zinc-Protein-Chelant Interactions using Gold Nanoparticles Functionalized with Zinc-Responsive Polypeptides”, 2014, Submitted. ( ${ }^{\dagger}$ Equal contribution)

JR2EC functionalized gold nanoparticles was used as a real time model system for probing $\mathrm{Zn}^{2+}$-mediated interactions between low molecular weight chelants and polypeptides. The JR2EC functionalized gold nanoparticles aggregated extensively in the presence of $\mathrm{Zn}^{2+}$, as a result of dimerization and folding, resulting in a redshift of the plasmon band. Chelants affected the model system differently depending on their concentrations, affinity towards $\mathrm{Zn}^{2+}$ and coordination number, which was reflected by the magnitude of the shift of the plasmon band. The effects of four different chelants were investigated; phytic acid, folic acid, oxalic acid and EDTA. The formation of ternary complexes between $\mathrm{Zn}^{2+}$, chelant and the immobilized JR2EC which interfered in the dimerization and thus prevented aggregation was found to be an important factor that significantly decreased the colorimetric response. Redispersion of aggregated particles was also investigated and was found to correlate with the affinity of the chelants for $\mathrm{Zn}^{2+}$. 


\section{PAPER IV}

R. Selegård, K. Enander, D. Aili, ”Generic Phosphatase Activity Detection using Zinc Mediated Aggregation Modulation of Polypeptide-Modified Gold Nanoparticles”, 2014, Submitted.

This paper describes a generic bioassay for phosphatase activity detection using $\mathrm{Zn}^{2+}$ responsive polypeptide (JR2EC) functionalized gold nanoparticles. The enzymatic degradation of phosphate containing substrates produces inorganic phosphate as a byproduct which markedly reduces the concentration of available $\mathrm{Zn}^{2+}$ in a solution. This was transduced into an optical signal using the $\mathrm{Zn}^{2+}$-induced aggregation of JR2EC modified gold nanoparticles. The versatility of this assay was demonstrated using three different phosphatases; alkaline phosphatase, pyrophosphatase and apyrase, and five different substrates; ATP, ADP, AMP, GTP and pyrophosphate. Phosphatase activity was studied both as a function of time and enzyme concentration, and all phosphatase could be detected in the low nanomolar range. The assay was further used for both characterization of enzyme substrate specificity and effects of inhibitors on the enzymatic activity. 


\section{CHAPTER 10}

Future Outlook

Almost two decades after Mirkin's first description of colorimetric gold nanoparticle based assay, ${ }^{26}$ published in 1996, the field is still evolving and encompasses assays for most classes of biomolecules, however the need for new rapid and accurate sensors that are easily interpreted are still present and perhaps greater than ever before.

In this thesis a glimpse of the possible applications of polypeptide assembled hybrid nanomaterials is described. The use of JR2EC decorate nanoparticles as components in bioanalytical assays have proven to be a viable option as the attained nanomaterial possesses a high colloidal stability that can easily and specifically be tuned. Its further use in sensor applications is easily imagined, however small alterations to the strategies already demonstrated would allow for detection of new analytes, and improvements can always be made:

In paper $I$ a versatile approach was demonstrated that can easily be applied to more relevant targets by immobilizing alternative receptors.

In paper II a relevant target is already chosen but the assay must be further refined to address unspecific adsorption of proteins present in saliva that occurs in live samples. Testing of the assay using clinical samples from patients suffering from cancer is planned.

In paper III the particle systems response to the presences of chelants is investigated and can be further extended to include additional chelants to study how they interact with proteins.

In paper IV the generic approach to determine phosphatase activity can easily be extended to any reaction that causes a change to the coordination capability of the sample, regardless if its enzymatically catalyzed or not. It further does not matter if the change is an increase or decrease as it is only a question of setting the initial concentration of the starting material to an appropriate value. This assay is also suitable for high-throughput drug screening. 
For the time being I leave these further refinements of the particle based assays to others, as I plunge head-deep into the promised land of hydrogels. In this project which will be conducted in the group of Daniel Aili, I will develop a generic click-chemistry-based strategy for covalent grafting of JR2EC and its complementary polypeptide (JR2KC) and carbohydrates to biocompatible polymers, that will enable straightforward synthesis and self-assembly of biofunctional and responsive peptide-polymer hybrid hydrogels. The overall aim of the project is to develop a set of mutually compatible building blocks (peptides, polymers and bioactive motifs) for modular bottom-up fabrication of biofunctional hydrogels. 


\section{CHAPTER 11}

References

1. Feynman, R. P., There's Plenty of Room at the Bottom - An Invitation to Enter a New Field of Physics. Caltech Engineering and Science 1960, 23 (5), 22-36.

2. Willets, K. A.; Van Duyne, R. P., Localized Surface Plasmon Resonance Spectroscopy and Sensing. Annual Review of Physical Chemistry 2007, 58 (1), 267-297.

3. Nanoscience and Nanotechnologies: opportunities and uncertainties. The Royal Sovitey \& The Royal Academy of Engineering: London, 2004.

4. Seife, C., Blunting Nature's Swiss Army Knife. Science 1997, 277 (5332), 1602-1603.

5. Guarise, C.; Pasquato, L.; De Filippis, V.; Scrimin, P., Gold nanoparticles-based protease assay. Proceedings of the National Academy of Sciences of the United States of America 2006, 103 (11), 3978-3982.

6. Lee, J.-S.; Han, M. S.; Mirkin, C. A., Colorimetric Detection of Mercuric Ion (Hg2+) in Aqueous Media using DNAFunctionalized Gold Nanoparticles. Angewandte Chemie International Edition 2007, 46 (22), 4093-4096.

7. Aili, D.; Mager, M.; Roche, D.; Stevens, M. M., Hybrid Nanoparticle-Liposome Detection of Phospholipase Activity. Nano Letters 2010, 11 (4), 1401-1405.

8. de la Rica, R.; Stevens, M. M., Plasmonic ELISA for the ultrasensitive detection of disease biomarkers with the naked eye. Nat Nano 2012, 7 (12), 821-824.

9. Rodríguez-Lorenzo, L.; de la Rica, R.; Álvarez-Puebla, R. A.; Liz-Marzán, L. M.; Stevens, M. M., Plasmonic nanosensors with inverse sensitivity by means of enzyme-guided crystal growth. Nat Mater 2012, 11 (7), 604-607.

10. Lehn, J.-M., Supramolecular Chemistry—Scope and Perspectives Molecules, Supermolecules, and Molecular Devices (Nobel Lecture). Angewandte Chemie International Edition in English 1988, 27 (1), 89-112.

11. Wolf, K. L.; Frahm, H.; Harms, H., The State of Arrangement of Molecules in Liquids. Z. Phys. Chem. Abt. B 1937, 36, 237-287.

12. Steed, J. W.; Turner, D. R.; Wallace, K. J., Core concepts in supramolecular chemistry and nanochemistry. John Wiley and Sons: Chichester, 2007.

13. Anslyn, E. V.; Dougherty, D. A., Modern physical organic chemistry. University Science Books: California, 2006.

14. Whitesides, G. M.; Grzybowski, B., Self-Assembly at All Scales. Science 2002, 295 (5564), 2418-2421.

15. Whitesides, G. M.; Boncheva, M., Beyond molecules: Self-assembly of mesoscopic and macroscopic components. Proceedings of the National Academy of Sciences 2002, 99 (8), 4769-4774.

16. Whitesides, G.; Mathias, J.; Seto, C., Molecular self-assembly and nanochemistry: a chemical strategy for the synthesis of nanostructures. Science 1991, 254 (5036), 1312-1319.

17. Stanley, W. M., Nobel Lecture: The Isolation and Properties of Crystalline Tobacco Mosaic Virus. Nobelprize.org. Nobel Media AB 2013. .

18. Namba, K.; Stubbs, G., Structure of tobacco mosaic virus at 3.6 A resolution: implications for assembly. Science 1986, 231 (4744), 1401-1406.

19. Stock, D.; Leslie, A. G. W.; Walker, J. E., Molecular Architecture of the Rotary Motor in ATP Synthase. Science 1999, 286 (5445), 1700-1705.

20. Seeman, N. C., DNA in a material world. Nature 2003, 421 (6921), 427-431.

21. Yan, H.; Zhang, X.; Shen, Z.; Seeman, N. C., A robust DNA mechanical device controlled by hybridization topology. Nature 2002, 415 (6867), 62-65.

22. Winfree, E.; Liu, F.; Wenzler, L. A.; Seeman, N. C., Design and self-assembly of two-dimensional DNA crystals. Nature 1998, 394 (6693), 539-544.

23. Rothemund, P. W. K., Folding DNA to create nanoscale shapes and patterns. Nature 2006, 440 (7082), $297-302$.

24. He, Y.; Ye, T.; Su, M.; Zhang, C.; Ribbe, A. E.; Jiang, W.; Mao, C., Hierarchical self-assembly of DNA into symmetric supramolecular polyhedra. Nature 2008, 452 (7184), 198-201.

25. Andersen, E. S.; Dong, M.; Nielsen, M. M.; Jahn, K.; Subramani, R.; Mamdouh, W.; Golas, M. M.; Sander, B.; Stark, H.; Oliveira, C. L. P.; Pedersen, J. S.; Birkedal, V.; Besenbacher, F.; Gothelf, K. V.; Kjems, J., Self-assembly of a nanoscale DNA box with a controllable lid. Nature 2009, 459 (7243), 73-76.

26. Mirkin, C. A.; Letsinger, R. L.; Mucic, R. C.; Storhoff, J. J., A DNA-based method for rationally assembling nanoparticles into macroscopic materials. Nature 1996, 382 (6592), 607-609. 
27. Williams, S. C. P., Spherical nucleic acids: A whole new ball game. Proceedings of the National Academy of Sciences 2013, 110 (33), 13231-13233.

28. Mann, S.; Shenton, W.; Li, M.; Connolly, S.; Fitzmaurice, D., Biologically Programmed Nanoparticle Assembly. Advanced Materials 2000, 12 (2), 147-150.

29. Connolly, S.; Fitzmaurice, D., Programmed Assembly of Gold Nanocrystals in Aqueous Solution. Advanced Materials 1999, 11 (14), 1202-1205.

30. Rydberg, J.; Baltzer, L.; Sarojini, V., Intrinsically unstructured proteins by design-electrostatic interactions can control binding, folding, and function of a helix-loop-helix heterodimer. Journal of Peptide Science 2013, 19 (8), 461 469.

31. Baltzer, L.; Nilsson, H.; Nilsson, J., De Novo Design of ProteinsWhat Are the Rules? Chemical Reviews 2001, 101 (10), 3153-3164.

32. Enander, K.; Dolphin, G. T.; Liedberg, B.; Lundström, I.; Baltzer, L., A Versatile Polypeptide Platform for Integrated Recognition and Reporting: Affinity Arrays for Protein-Ligand Interaction Analysis. Chemistry - A European Journal 2004, 10 (10), 2375-2385.

33. Hartgerink, J. D.; Beniash, E.; Stupp, S. I., Self-Assembly and Mineralization of Peptide-Amphiphile Nanofibers. Science 2001, 294 (5547), 1684-1688.

34. Aggeli, A.; Bell, M.; Boden, N.; Keen, J. N.; Knowles, P. F.; McLeish, T. C. B.; Pitkeathly, M.; Radford, S. E., Responsive gels formed by the spontaneous self-assembly of peptides into polymeric [beta]-sheet tapes. Nature 1997, 386 (6622), 259-262.

35. Ghadiri, M. R.; Granja, J. R.; Milligan, R. A.; McRee, D. E.; Khazanovich, N., Self-assembling organic nanotubes based on a cyclic peptide architecture. Nature 1993, 366 (6453), 324-327.

36. Aili, D.; Enander, K.; Rydberg, J.; Lundström, I.; Baltzer, L.; Liedberg, B., Aggregation-Induced Folding of a De Novo Designed Polypeptide Immobilized on Gold Nanoparticles. Journal of the American Chemical Society 2006, 128 (7), 2194-2195.

37. Aili, D.; Enander, K.; Rydberg, J.; Nesterenko, I.; Björefors, F.; Baltzer, L.; Liedberg, B., Folding Induced Assembly of Polypeptide Decorated Gold Nanoparticles. Journal of the American Chemical Society 2008, 130 (17), 5780-5788.

38. Hull, D.; Clyne, T. W., An introduction to composite materials / D. Hull and T.W. Clyne. Cambridge : Cambridge Univ. Press, 1996

2. ed.: 1996.

39. Meyers, M.; Lin, A. M.; Seki, Y.; Chen, P.-Y.; Kad, B.; Bodde, S., Structural biological composites: An overview. JOM 2006, 58 (7), 35-41.

40. Wagner, H. D., Nanocomposites: Paving the way to stronger materials. Nat Nano 2007, 2 (12), 742-744.

41. Sanchez, C.; Belleville, P.; Popall, M.; Nicole, L., Applications of advanced hybrid organic-inorganic nanomaterials: from laboratory to market. Chem Soc Rev 2011, 40 (2), 696-753.

42. Bridot, J.-L.; Faure, A.-C.; Laurent, S.; Rivière, C.; Billotey, C.; Hiba, B.; Janier, M.; Josserand, V.; Coll, J.-L.; Vander Elst, L.; Muller, R.; Roux, S.; Perriat, P.; Tillement, O., Hybrid Gadolinium Oxide Nanoparticles: Multimodal Contrast Agents for in Vivo Imaging. Journal of the American Chemical Society 2007, 129 (16), 5076-5084.

43. Biosensing using nanomaterials. John Wiley \& Sons: New Jersey, 2009.

44. Ajayan, P. M.; Schadler, L. S.; Braun, P. V., Nanocomposite science and technology. Wiley-VCH: Weinheim, 2003.

45. Chauhan, B. P., Hybrid nanomaterials: synthesis, characterization, and applications / edited by Bhanu P.S. Chauhan. Hoboken, N.J. : Wiley, c2011.: 2011.

46. Sanchez, C.; Julian, B.; Belleville, P.; Popall, M., Applications of hybrid organic-inorganic nanocomposites. Journal of Materials Chemistry 2005, 15 (35-36), 3559-3592.

47. Aili, D.; Stevens, M. M., Bioresponsive peptide-inorganic hybrid nanomaterials. Chem Soc Rev 2010, 39 (9), $3358-$ 3370.

48. Fersht, A., Structure and mechanism in protein science. W. H. Freeman and Company: New York, 1999.

49. Creighton, T. E., Proteins: Structures and molecular properties. W. H. Freeman and company: New York, 1993.

50. Mani, R.; Tang, M.; Wu, X.; Buffy, J. J.; Waring, A. J.; Sherman, M. A.; Hong, M., Membrane-Bound Dimer Structure of a $\beta$-Hairpin Antimicrobial Peptide from Rotational-Echo Double-Resonance Solid-State NMR $†$. Biochemistry 2006, 45 (27), 8341-8349.

51. Sun, Y.; Parker, M. H.; Weigele, P.; Casjens, S.; Prevelige Jr, P. E.; Krishna, N. R., Structure of the coat proteinbinding domain of the scaffolding protein from a double-stranded DNA virus. Journal of Molecular Biology 2000, 297 (5), 1195-1202.

52. Go, A.; Kim, S.; Baum, J.; Hecht, M. H., Structure and dynamics of de novo proteins from a designed superfamily of 4helix bundles. Protein Science 2008, 17 (5), 821-832.

53. Berman, H. M.; Westbrook, J.; Feng, Z.; Gilliland, G.; Bhat, T. N.; Weissig, H.; Shindyalov, I. N.; Bourne, P. E., The Protein Data Bank. Nucleic Acids Research 2000, 28 (1), 235-242.

54. Porollo, A. A.; Adamczak, R.; Meller, J., POLYVIEW: a flexible visualization tool for structural and functional annotations of proteins. Bioinformatics 2004, 20 (15), 2460-2462.

55. Branden, C.; Tooze, J., Indroduction to protein structure. Garland publishing: New York, 1998.

56. Onuchic, J. N.; Wolynes, P. G., Theory of protein folding. Current Opinion in Structural Biology 2004, 14 (1), $70-75$. 
57. Greenfield, N. J.; Fasman, G. D., Computed circular dichroism spectra for the evaluation of protein conformation. Biochemistry 1969, 8 (10), 4108-4116.

58. Johnson, W. C., Protein secondary structure and circular dichroism: A practical guide. Proteins: Structure, Function, and Bioinformatics 1990, 7 (3), 205-214.

59. Kelly, S. M.; Price, N. C., The Use of Circular Dichroism in the Investigation of Protein Structure and Function. Current Protein and Peptide Science 2000, 1 (4), 349-384.

60. Dong, H.; Paramonov, S. E.; Aulisa, L.; Bakota, E. L.; Hartgerink, J. D., Self-Assembly of Multidomain Peptides: Balancing Molecular Frustration Controls Conformation and Nanostructure. Journal of the American Chemical Society 2007, 129 (41), 12468-12472.

61. Padmanabhan, S.; York, E. J.; Stewart, J. M.; Baldwin, R. L., Helix Propensities of Basic Amino Acids Increase with the Length of the Side-chain. Journal of Molecular Biology 1996, 257 (3), 726-734.

62. Lundqvist, M.; Nygren, P.; Jonsson, B.-H.; Broo, K., Induction of Structure and Function in a Designed Peptide upon Adsorption on a Silica Nanoparticle. Angewandte Chemie International Edition 2006, 45 (48), 8169-8173.

63. Nygren, P.; Lundqvist, M.; Liedberg, B.; Jonsson, B.-H.; Ederth, T., Secondary Structure in de Novo Designed Peptides Induced by Electrostatic Interaction with a Lipid Bilayer Membrane. Langmuir 2010, 26 (9), 6437-6448.

64. Enander, K.; Aili, D.; Baltzer, L.; Lundström, I.; Liedberg, B., Alpha-Helix-Inducing Dimerization of Synthetic Polypeptide Scaffolds on Gold. Langmuir 2005, 21 (6), 2480-2487.

65. Pochan, D. J.; Schneider, J. P.; Kretsinger, J.; Ozbas, B.; Rajagopal, K.; Haines, L., Thermally Reversible Hydrogels via Intramolecular Folding and Consequent Self-Assembly of a de Novo Designed Peptide. Journal of the American Chemical Society 2003, 125 (39), 11802-11803.

66. Kohn, W. D.; Kay, C. M.; Sykes, B. D.; Hodges, R. S., Metal Ion Induced Folding of a de Novo Designed Coiled-Coil Peptide. Journal of the American Chemical Society 1998, 120 (6), 1124-1132.

67. Li, X.; Suzuki, K.; Kashiwada, A.; Hiroaki, H.; Kohda, D.; Tanaka, T., Soft metal ions, Cd(II) and Hg (II), induce triple-stranded $\alpha$-helical assembly and folding of a de novo designed peptide in their trigonal geometries. Protein Science 2000, 9 (7), 1327-1333.

68. Enander, K. Folded Polypeptide Scaffolds for Biosensor and Biochip Applications - Design, Synthesis, Functionalization and Characterisation. Linköping Univeristy, Linköping, 2003.

69. Aili, D. Polypeptide-Based Nanoscale Materials. Linköping University, Linköping, 2008.

70. Enander, K.; Dolphin, G. T.; Andersson, L. K.; Liedberg, B.; Lundström, I.; Baltzer, L., Designed, Folded Polypeptide Scaffolds That Combine Key Biosensing Events of Recognition and Reporting. The Journal of Organic Chemistry 2002, 67 (9), 3120-3123.

71. Enander, K.; Dolphin, G. T.; Baltzer, L., Designed, Functionalized Helix-Loop-Helix Motifs that Bind Human Carbonic Anhydrase II: A New Class of Synthetic Receptor Molecules. Journal of the American Chemical Society 2004, 126 (14), 4464-4465.

72. Merrifield, R. B., Solid Phase Peptide Synthesis. I. The Synthesis of a Tetrapeptide. Journal of the American Chemical Society 1963, 85 (14), 2149-2154.

73. Merrifield, R. B., Automated Synthesis of Peptides. Science 1965, 150 (3693), 178-185.

74. Gutte, B., Peptides: synthesis, structures, and applications. Academic Press: San Diego, USA, 1995.

75. Lam, K. S.; Salmon, S. E.; Hersh, E. M.; Hruby, V. J.; Kazmierski, W. M.; Knapp, R. J., A new type of synthetic peptide library for identifying ligand-binding activity. Nature 1991, 354 (6348), 82-84.

76. Marshall, G. R., Solid-phase synthesis: a paradigm shift. Journal of Peptide Science 2003, 9 (9), 534-544.

77. Dawson, P.; Muir, T.; Clark-Lewis, I.; Kent, S., Synthesis of proteins by native chemical ligation. Science 1994, 266 (5186), 776-779.

78. Canne, L. E.; Ferre- D'Amare, A. R.; Burley, S. K.; Kent, S. B. H., Total Chemical Synthesis of a Unique Transcription Factor-Related Protein: cMyc-Max. Journal of the American Chemical Society 1995, 117 (11), 2998-3007.

79. Karas, M.; Hillenkamp, F., Laser desorption ionization of proteins with molecular masses exceeding 10,000 daltons. Analytical Chemistry 1988, 60 (20), 2299-2301.

80. Tanaka, K.; Waki, H.; Ido, Y.; Akita, S.; Yoshida, Y.; Yoshida, T.; Matsuo, T., Protein and polymer analyses up to m/z 100000 by laser ionization time-of-flight mass spectrometry. Rapid Communications in Mass Spectrometry 1988, 2 (8), 151-153.

81. Kolb, H. C.; Finn, M. G.; Sharpless, K. B., Click Chemistry: Diverse Chemical Function from a Few Good Reactions. Angewandte Chemie International Edition 2001, 40 (11), 2004-2021.

82. Hegetschweiler, K.; Saltman, P., Interaction of copper(II) with N-(2-hydroxyethyl)piperazine-N'-ethanesulfonic acid (HEPES). Inorganic Chemistry 1986, 25 (1), 107-109.

83. Crichton, R. R., Biological inorganic chemistry : an introduction / Robert R. Crichton with the collaboration of Fre deric Lallemand, Ionna S.M. Psalti and Roberta J Ward. Amsterdam ; Oxford : Elsevier, 2008.: 2008.

84. Dudev, T.; Lim, C., Metal Binding Affinity and Selectivity in Metalloproteins: Insights from Computational Studies. Annual Review of Biophysics 2008, 37 (1), 97-116.

85. De Wall, S. L.; Meadows, E. S.; Barbour, L. J.; Gokel, G. W., Synthetic receptors as models for alkali metal cation- $\pi$ binding sites in proteins. Proceedings of the National Academy of Sciences 2000, 97 (12), 6271-6276.

86. Berg, J. M.; Shi, Y., The Galvanization of Biology: A Growing Appreciation for the Roles of Zinc. Science 1996, 271 (5252), 1081-1085. 
87. Yamashita, M. M.; Wesson, L.; Eisenman, G.; Eisenberg, D., Where metal ions bind in proteins. Proceedings of the National Academy of Sciences 1990, 87 (15), 5648-5652.

88. Tripp, B. C.; Smith, K.; Ferry, J. G., Carbonic Anhydrase: New Insights for an Ancient Enzyme. Journal of Biological Chemistry 2001, 276 (52), 48615-48618.

89. Browner, M. F.; Smith, W. W.; Castelhano, A. L., Crystal structures of matrilysin-inhibitor complexes. Biochemistry 1995, 34 (20), 6602-6610.

90. Stec, B.; Holtz, K. M.; Kantrowitz, E. R., A revised mechanism for the alkaline phosphatase reaction involving three metal ions. Journal of Molecular Biology 2000, 299 (5), 1303-1311.

91. Eriksson, A. E.; Jones, T. A.; Liljas, A., Refined structure of human carbonic anhydrase II at 2.0 Å resolution. Proteins: Structure, Function, and Bioinformatics 1988, 4 (4), 274-282.

92. Holm, R. H.; Kennepohl, P.; Solomon, E. I., Structural and Functional Aspects of Metal Sites in Biology. Chemical Reviews 1996, 96 (7), 2239-2314.

93. Christianson, D. W., Structural biology of zinc. Advances in protein chemistry 1991, 42, 281-355.

94. Brown, K. H.; Wuehler, S. E.; Peerson, J. M., The importance of zinc in human nutrition and estimation of the global prevalence of zinc deficiency. Food and Nutrition Bulletin 2001, 22 (2), 113-125.

95. Tamura, T.; Goldenberg, R. L., Zinc nutriture and pregnancy outcome. Nutrition Research 1996, 16 (1), $139-181$.

96. Welch, R. M.; Graham, R. D., A new paradigm for world agriculture: Meeting human needs. Productive, sustainable, nutritious. Field Crops Research 1999, 60 (1-2), 1-10.

97. Prasad, A. S., Discovery and importance of zinc in human nutrition. Federation Proceedings 1984, 43 (13), $2829-2834$.

98. Shears, S. B., The versatility of inositol phosphates as cellular signals. Biochimica et Biophysica Acta (BBA) Molecular and Cell Biology of Lipids 1998, 1436 (1-2), 49-67.

99. Kies, A. K.; De Jonge, L. H.; Kemme, P. A.; Jongbloed, A. W., Interaction between Protein, Phytate, and Microbial Phytase. In Vitro Studies. Journal of Agricultural and Food Chemistry 2006, 54 (5), 1753-1758.

100. Sigel, H.; Bianchi, E. M.; Corfù, N. A.; Kinjo, Y.; Tribolet, R.; Martin, R. B., Stabilities and Isomeric Equilibria in Solutions of Monomeric Metal-Ion Complexes of Guanosine 5'-Triphosphate (GTP4-) and Inosine 5'-Triphosphate (ITP4-) in Comparison with Those of Adenosine 5'-Triphosphate (ATP4-). Chemistry - A European Journal 2001, 7 (17), 3729-3737.

101. Terkeltaub, R. A., Inorganic pyrophosphate generation and disposition in pathophysiology. American Journal of Physiology 2001, 281, C1-C11.

102. Sigel, H.; Griesser, R., Nucleoside 5'-triphosphates: self-association, acid-base, and metal ion-binding properties in solution. Chem Soc Rev 2005, 34 (10), 875-900.

103. Clever, H. L.; Derrick, M. E.; Johnson, S. A., The Solubility of Some Sparingly Soluble Salts of Zinc and Cadmium in Water and in Aqueous Electrolyte Solutions. Journal of Physical and Chemical Reference Data 1992, 21 (5), 9411004 .

104. Han, F. X., Biogeochemistry of trace Elements in Arid Environments. Springer: Dordrecht, The Netherlands, 2007.

105. Bianchi, E. M.; Sajadi, S. A. A.; Song, B.; Sigel, H., Stabilities and Isomeric Equilibria in Aqueous Solution of Monomeric Metal Ion Complexes of Adenosine 5'-Diphosphate (ADP3-) in Comparison with Those of Adenosine 5'Monophosphate (AMP2-). Chemistry - A European Journal 2003, 9 (4), 881-892.

106. Azab, H. A.; Anwar, Z. M., Coordination Tendency of Some Biologically Important Zwitterionic Buffers toward Metal Ion Nucleotide Complexes at Different Temperatures. Journal of Chemical \& Engineering Data 2012, 57 (10), 28902895.

107. Daniel, M.-C.; Astruc, D., Gold Nanoparticles: Assembly, Supramolecular Chemistry, Quantum-Size-Related Properties, and Applications toward Biology, Catalysis, and Nanotechnology. Chemical Reviews 2003, 104 (1), 293346.

108. Higby, G., Gold in medicine. Gold Bulletin 1982, 15 (4), 130-140.

109. Maclagan, N. F., The preparation and use of colloidal gold sols as diagnostic agents. The british journal of experimental pathology 1946, 27 (6), 369-377.

110. Faraday, M., The Bakerian Lecture: Experimental Relations of Gold (and Other Metals) to Light. Philosophical Transactions of the Royal Society of London 1857, 147, 145-181.

111. Graham, T., Liquid Diffusion Applied to Analysis. Philosophical Transactions of the Royal Society of London 1861, 151, 183-224.

112. Turkevich, J.; Stevenson, P. C.; Hillier, J., A study of the nucleation and growth processes in the synthesis of colloidal gold. Discussions of the Faraday Society 1951, 11 (0), 55-75.

113. Frens, G., Controlled Nucleation for the Regulation of the Particle Size in Monodisperse Gold Suspensions. nature physical science 1973, 241, 20-22.

114. Brust, M.; Walker, M.; Bethell, D.; Schiffrin, D. J.; Whyman, R., Synthesis of thiol-derivatised gold nanoparticles in a two-phase Liquid-Liquid system. Journal of the Chemical Society, Chemical Communications 1994, (7), 801-802.

115. Cheng, Y.; Schiffrin, D. J., Electrodeposition of metallic gold clusters at the water/1,2-dichloroethane interface. Journal of the Chemical Society, Faraday Transactions 1996, 92 (20), 3865-3871.

116. Foss, C. A.; Hornyak, G. L.; Stockert, J. A.; Martin, C. R., Template-Synthesized Nanoscopic Gold Particles: Optical Spectra and the Effects of Particle Size and Shape. The Journal of Physical Chemistry 1994, 98 (11), 2963-2971. 
117. Moeremans, M.; Daneels, G.; Van Dijck, A.; Langanger, G.; De Mey, J., Sensitive visualization of antigen-antibody reactions in dot and blot immune overlay assays with immunogold and immunogold/silver staining. Journal of Immunological Methods 1984, 74 (2), 353-360.

118. Hsu, Y.-H., Immunogold for detection of antigen on nitrocellulose paper. Analytical Biochemistry 1984, 142 (1), $221-$ 225.

119. Boisselier, E.; Astruc, D., Gold nanoparticles in nanomedicine: preparations, imaging, diagnostics, therapies and toxicity. Chem Soc Rev 2009, 38 (6), 1759-1782.

120. Mieszawska, A. J.; Mulder, W. J. M.; Fayad, Z. A.; Cormode, D. P., Multifunctional Gold Nanoparticles for Diagnosis and Therapy of Disease. Molecular Pharmaceutics 2013, 10 (3), 831-847.

121. Yeh, Y.-C.; Creran, B.; Rotello, V. M., Gold nanoparticles: preparation, properties, and applications in bionanotechnology. Nanoscale 2012, 4 (6), 1871-1880.

122. Hu, M.; Chen, J.; Li, Z.-Y.; Au, L.; Hartland, G. V.; Li, X.; Marquez, M.; Xia, Y., Gold nanostructures: engineering their plasmonic properties for biomedical applications. Chem Soc Rev 2006, 35 (11), 1084-1094.

123. Chah, S.; Hammond, M. R.; Zare, R. N., Gold Nanoparticles as a Colorimetric Sensor for Protein Conformational Changes. Chemistry \& Biology 12 (3), 323-328.

124. Dahl, J. A.; Maddux, B. L. S.; Hutchison, J. E., Toward Greener Nanosynthesis. Chemical Reviews 2007, 107 (6), 2228-2269.

125. Storhoff, J. J.; Elghanian, R.; Mucic, R. C.; Mirkin, C. A.; Letsinger, R. L., One-Pot Colorimetric Differentiation of Polynucleotides with Single Base Imperfections Using Gold Nanoparticle Probes. Journal of the American Chemical Society 1998, 120 (9), 1959-1964.

126. Cortie, M. B., The weird world of nanoscale gold. Gold Bulletin 2004, 37 (1-2), 12-19.

127. Szunerits, S.; Boukherroub, R., Sensing using localised surface plasmon resonance sensors. Chem Commun (Camb) 2012, 48 (72), 8999-9010.

128. Petryayeva, E.; Krull, U. J., Localized surface plasmon resonance: Nanostructures, bioassays and biosensing—A review. Analytica Chimica Acta 2011, 706 (1), 8-24.

129. Martinsson, E.; Sepulveda, B.; Chen, P.; Elfwing, A.; Liedberg, B.; Aili, D., Optimizing the Refractive Index Sensitivity of Plasmonically Coupled Gold Nanoparticles. Plasmonics 2013, 1-8.

130. Martinsson, E.; Shahjamali, M. M.; Enander, K.; Boey, F.; Xue, C.; Aili, D.; Liedberg, B., Local Refractive Index Sensing Based on Edge Gold-Coated Silver Nanoprisms. The Journal of Physical Chemistry C 2013, 117 (44), 2314823154.

131. Sepúlveda, B.; Angelomé, P. C.; Lechuga, L. M.; Liz-Marzán, L. M., LSPR-based nanobiosensors. Nano Today 2009, 4 (3), 244-251.

132. Chen, C.-F.; Tzeng, S.-D.; Chen, H.-Y.; Lin, K.-J.; Gwo, S., Tunable Plasmonic Response from AlkanethiolateStabilized Gold Nanoparticle Superlattices: Evidence of Near-Field Coupling. Journal of the American Chemical Society 2007, 130 (3), 824-826.

133. Rechberger, W.; Hohenau, A.; Leitner, A.; Krenn, J. R.; Lamprecht, B.; Aussenegg, F. R., Optical properties of two interacting gold nanoparticles. Optics Communications 2003, 220 (1-3), 137-141.

134. Su, K. H.; Wei, Q. H.; Zhang, X.; Mock, J. J.; Smith, D. R.; Schultz, S., Interparticle Coupling Effects on Plasmon Resonances of Nanogold Particles. Nano Letters 2003, 3 (8), 1087-1090.

135. Israelachvili, J., Intermolecular and surface forces. Academic Press: Lonon, 1992.

136. Parsegian, V. A.; Zemb, T., Hydration forces: Observations, explanations, expectations, questions. Current Opinion in Colloid \& Interface Science 2011, 16 (6), 618-624.

137. Fritz, G.; Schädler, V.; Willenbacher, N.; Wagner, N. J., Electrosteric Stabilization of Colloidal Dispersions. Langmuir 2002, 18 (16), 6381-6390.

138. Nakanishi, K.; Sakiyama, T.; Imamura, K., On the adsorption of proteins on solid surfaces, a common but very complicated phenomenon. Journal of Bioscience and Bioengineering 2001, 91 (3), 233-244.

139. Oura, K.; Lifshits, V. G.; Saranin, A. A.; Zotov, A. V., Surface Science: An Introduction. Springer: 2010.

140. Dubois, L. H.; Nuzzo, R. G., Synthesis, Structure, and Properties of Model Organic Surfaces. Annual Review of Physical Chemistry 1992, 43 (1), 437-463.

141. Ulman, A., Formation and Structure of Self-Assembled Monolayers. Chemical Reviews 1996, 96 (4), $1533-1554$.

142. Leff, D. V.; Ohara, P. C.; Heath, J. R.; Gelbart, W. M., Thermodynamic Control of Gold Nanocrystal Size: Experiment and Theory. The Journal of Physical Chemistry 1995, 99 (18), 7036-7041.

143. Aili, D.; Enander, K.; Baltzer, L.; Liedberg, B., Assembly of Polypeptide-Functionalized Gold Nanoparticles through a Heteroassociation- and Folding-Dependent Bridging. Nano Letters 2008, 8 (8), 2473-2478.

144. Green, F., The Colloidal Gold Reaction of the Cerebrospinal Fluid. Canadian Medical Association 1925, 15 (11), 1139 1143.

145. Page Faulk, W.; Malcolm Taylor, G., Communication to the editors: An immunocolloid method for the electron microscope. Immunochemistry 1971, 8 (11), 1081-1083.

146. Slot, J. W.; Geuze, H. J., A new method of preparing gold probes for multiple-labeling cytochemistry. European Journal of Cell Biology 1985, 38 (1), 87-93.

147. Wilson, R., The use of gold nanoparticles in diagnostics and detection. Chem Soc Rev 2008, 37 (9), $2028-2045$. 
148. Leuvering, J. H. W.; Thal, P. J. H. M.; Van der Waart, M.; Schuurs, A. H. W. M., A sol particle agglutination assay for human chorionic gonadotrophin. Journal of Immunological Methods 1981, 45 (2), 183-194.

149. Leuvering, J. H. W.; Thal, P. J. H. M.; Waart, M. v. d.; Schuurs, A. H. W. M., Sol Particle Immunoassay (SPIA). Journal of Immunoassay 1980, 1 (1), 77-91.

150. Zhou, Y.; Yang, Z.; Xu, M., Colorimetric detection of lysine using gold nanoparticles aggregation. Analytical Methods 2012, 4 (9), 2711-2714.

151. Zhang, M.; Qing, G.; Xiong, C.; Cui, R.; Pang, D.-W.; Sun, T., Dual-Responsive Gold Nanoparticles for Colorimetric Recognition and Testing of Carbohydrates with a Dispersion-Dominated Chromogenic Process. Advanced Materials 2013, 25 (5), 749-754.

152. Laromaine, A.; Koh, L.; Murugesan, M.; Ulijn, R. V.; Stevens, M. M., Protease-Triggered Dispersion of Nanoparticle Assemblies. Journal of the American Chemical Society 2007, 129 (14), 4156-4157.

153. Zhao, W.; Chiuman, W.; Lam, J. C. F.; Brook, M. A.; Li, Y., Simple and rapid colorimetric enzyme sensing assays using non-crosslinking gold nanoparticle aggregation. Chem Commun (Camb) 2007, (36), 3729-3731.

154. Kaplan, J.; DeGrado, W. F., De novo design of catalytic proteins. Proceedings of the National Academy of Sciences of the United States of America 2004, 101 (32), 11566-11570.

155. Ryadnov, M. G.; Ceyhan, B.; Niemeyer, C. M.; Woolfson, D. N., "Belt and Braces": A Peptide-Based Linker System of de Novo Design. Journal of the American Chemical Society 2003, 125 (31), 9388-9394.

156. Stevens, M. M.; Flynn, N. T.; Wang, C.; Tirrell, D. A.; Langer, R., Coiled-Coil Peptide-Based Assembly of Gold Nanoparticles. Advanced Materials 2004, 16 (11), 915-918.

157. Luukkaa, H.; Klemi, P.; Hirsimäki, P.; Vahlberg, T.; Kivisaari, A.; Kähäri, V.-M.; Grénman, R., Matrix metalloproteinase (MMP)-7 in salivary gland cancer. Acta Oncologica 2010, 49 (1), 85-90.

158. Sanghamitra, N. J. M.; Ueno, T., Expanding coordination chemistry from protein to protein assembly. Chem Commun (Camb) 2013, 49 (39), 4114-4126.

159. Rezaei-Ghaleh, N.; Giller, K.; Becker, S.; Zweckstetter, M., Effect of Zinc Binding on $\beta$-Amyloid Structure and Dynamics: Implications for A $\beta$ Aggregation. Biophysical Journal 2011, 101 (5), 1202-1211.

160. Hegde, M. L.; Bharathi, P.; Suram, A.; Venugopal, C.; Jagannathan, R.; Poddar, P.; Srinivas, P.; Sambamurti, K.; Rao, K. J.; Scancar, J.; Messori, L.; Zecca, L.; Zatta, P., Challenges Associated with Metal Chelation Therapy in Alzheimer's Disease. Journal of Alzheimer's Disease 2009, 17 (3), 457-468. 


\section{Publications}

The articles associated with this thesis have been removed for copyright reasons. For more details about these see:

http://urn.kb.se/resolve?urn=urn:nbn:se:liu:diva-106719 